\title{
Structural response of concrete-filled round-ended stub columns subjected to eccentric loads
}

\author{
A. Piquer ${ }^{\text {a }}$, C. Ibañez ${ }^{\text {a*}}$, D. Hernández-Figueirido ${ }^{a}$ \\ ${ }^{a}$ Department of Mechanical Engineering and Construction, \\ Universitat Jaume I, Castellón, Spain \\ *Corresponding author: ibanezc@uji.es
}

\begin{abstract}
In this paper, the results of an experimental campaign on 9 concrete-filled round-ended steel tubular (CFRT) stub beam-columns subjected to eccentric loads are presented. Different levels of load eccentricity were considered including reference specimens subjected to concentric loads. In order to study the effect of the concrete infill strength in the ultimate capacity, two types of concrete infill were employed: normal and high strength concrete. In view of the experimental results, the dependency of the type of response on the load eccentricity and strength of concrete infill of the beam-columns was analysed. In addition to the effect of the concrete infill, the result of the composite action and the level of ductility were also studied by means of different parameters. It was found that the cross-sectional capacity is inversely proportional to the load eccentricity and that, in addition, it is highly sensitive to the region within the cross-section where the load application point lies. The experimental ultimate loads of the specimens were compared with the corresponding failure loads given by Eurocode 4 as well as with the combined axial force-bending moment interaction curve. In this case, the comparison showed that for high load eccentricities, code predictions are too conservative. Finally, an approach based on an equivalent rectangular CFST cross-section is presented and applied to calculate the capacity of tested columns, obtaining accurate predictions.
\end{abstract}

Keywords: concrete-filled steel beam-columns; round-ended beam-columns; eccentric loads; high strength concrete; sectional capacity; stub beam-columns. 


\section{NOTATION}

L length of the specimen

B major axis length of the round-ended steel tube

D minor axis length of the round-ended steel tube

e eccentricity

$\mathrm{N} \quad$ axial load

M bending moment

$\mathrm{N}_{\exp } \quad$ experimental ultimate bearing capacity

Nhollow,EC3 theoretical capacity of the steel hollow tube according to Eurocode 3

NEC4 theoretical capacity of the column according to Eurocode 4

$\mathrm{fc}_{\mathrm{c}} \quad$ compressive concrete strength $(150 \times 300 \mathrm{~mm}$ cylinder test $)$

$\mathrm{f}_{\mathrm{y}} \quad$ yielding strength of the steel tube

$\mathrm{f}_{\mathrm{u}} \quad$ ultimate strength of the steel tube

As cross-sectional area of the steel tube

$\mathrm{A}_{\mathrm{c}} \quad$ cross-sectional area of the concrete core

$\mathrm{h}_{\mathrm{n}} \quad$ positions of the plastic neutral axis within the CFST cross-section

$\mathrm{W}_{\mathrm{el}} \quad$ elastic section modulus of the hollow steel tube

$\mathrm{W}_{\mathrm{pa}} \quad$ plastic section modulus of the steel tube

$\mathrm{W}_{\mathrm{pan}} \quad$ plastic section modulus of the steel area within the region of $2 \mathrm{~h}_{\mathrm{n}}$ from the centre-line of the composite cross-section

$\mathrm{W}_{\mathrm{pc}} \quad$ plastic section modulus of the concrete core

$\mathrm{W}_{\mathrm{pcn}} \quad$ plastic section modulus of the concrete area within the region of $2 \mathrm{~h}_{\mathrm{n}}$ from the centre-line of the composite cross-section

$\mathrm{N}_{\mathrm{pl}} \quad$ plastic resistance under pure compression of the composite section

$\mathrm{M}_{\mathrm{pl}} \quad$ plastic moment resistance under pure bending of the composite section 


\section{INTRODUCTION}

In recent years, the use of concrete-filled steel tubular (CFST) columns has increased. Their high-quality structural characteristics, such as their high strength capacity, ductility, large energy absorption in case of seismic action or excellent fire resistance, make them an interesting and competitive option for the construction of high-rise buildings, bridges or warehouses. The steel tube provides permanent formwork to the concrete core and can also support the construction loads, which reduces material costs and construction time. Thus, at cross-section level, optimal economic designs of CFST columns can be found with respect to their equivalent steel or reinforced concrete columns, which allows taking advantage of all their benefits [1][2].

The enhancement in the mechanical response of these columns is due to the composite action between the hollow steel tube and the concrete core. The concrete core is confined by the steel tube which increases the compressive strength of the section and its ductility. In turn, the concrete infill prevents the steel tube from local buckling, particularly critical in rectangular CFST columns with thin-walled steel tubes. The effectiveness of the composite action is, in general, influenced by the cross-sectional aspect ratio, the strength of the materials and the confining factor, highly dependent of the cross-sectional shape [3].

The behaviour of CFST stub columns has been investigated by several researchers. A complete review of all the experimental campaigns and their details can be found in [4][5]. Accordingly, most of the tests carried out focused on circular, square or rectangular shapes, which are currently still the most used, Fig. 1. Confinement in circular sections is enhanced due to the hoop stresses appearing because of the composite action for both normal and high strength concrete (NSC and HSC). However, the effectiveness of the confinement decreases for other cross-sectional shapes, especially for HSC and its effect is still being studied [6]. 
In recent years, and parallel to these experimental campaigns, elliptical hollow steel tubes have been introduced to the construction industry to form this type of composite columns, Fig. 1c. The structural behaviour of elliptical CFST columns has been investigated both numerically and experimentally by several authors [7]-[14]. Their aesthetics combined with their structural advantage related to having different major and minor axis properties make these sections of great interest for designers. In fact, Sheehan et al. [15] carried out a series of tests on 8 eccentrically loaded elliptical CFST stub beam-columns. The experiments showed that the response was affected by the steel tube thickness, the load eccentricity and the bending axis.

An alternative to elliptical CFST columns is concrete-filled round-ended steel tubular (CFRT) columns, where the hollow steel tube consists of a rectangular section whose ends are capped off with semicircles, Fig. 1d. Thus, this novel shape combines the aesthetics of circular sections with the improved structural efficiency in bending of rectangular sections. Additionally, the flat sides of the section allow for the design of simpler joints to other structural elements.

The study of the behaviour of round-ended hollow sections [16][17] has been recently extended to concrete-filled members. However, despite all their advantages, only a limited number of works on CFRT columns can be found in the literature. An experimental campaign on 22 CFRT stub columns under compression was carried out by Ding et al. [18]. The authors also reported current applications of this type of composite sections as bridge pier columns, thus pointing out the necessity of investigating their structural performance. The length of the tested specimens ranged from 750 to $1600 \mathrm{~mm}$ and local buckling, mainly at the rectangular part, was observed at failure as in other typical geometries. However, all the columns were axially loaded during the tests. Only normal strength concrete was employed as infill 
(maximum cube strength of the concrete $57.4 \mathrm{MPa}$ ), and therefore there were no experimental results from specimens filled with high strength concrete.

Ding et al. [18] also developed a finite element model and a parametric study that revealed the high influence of the cross-sectional ratio, concrete strength and steel tube thickness on the ultimate capacity of the specimens. Subsequently, a design formula was proposed. In this context, the research presented by Hassanein and Patel [19] followed the same pattern. First, a finite model was developed which considered the distinct effect of the confinement by defining different concrete material models for the rectangular and the rounded areas respectively. After a parametric study to evaluate the effect of the concrete strength and cross-sectional aspect ratio, a formula to estimate the ultimate capacity of CFRT columns was proposed.

An attempt to study the behaviour of round-ended shapes on double-skin CFST stub columns was presented by Han et al. [20] in a research where tests on columns with other special cross-sectional shapes were also included and where two types of steel were combined: carbon and stainless steel tubes.

According to this review and due to the scarce number of investigations on the general response of CFRT columns, this paper presents a new experimental campaign on 9 CFRT stub beam-columns in order to study the influence of concrete strength and load eccentricity on the ultimate capacity of the specimens. Therefore, two different types of concrete are employed: normal and high strength concrete. In addition, the confinement effect is assessed since the columns are built with steel tubes whose wall thickness is relatively thin. As a novelty, the beam-columns are subjected to compression loads under various eccentricity values. After the corresponding analysis of the experimental results, these values are compared to those given by the Eurocode 4 [21] and, subsequently, a design approach based on an equivalent rectangular CFST cross-section is presented. 


\section{EXPERIMENTAL PROGRAM}

\subsection{Column specimens and test setup}

In this paper, the results of a series of tests carried out on eccentrically loaded CFRT stub beam-columns are presented. A total of 9 specimens were tested with the objective of evaluating the effect of the eccentricity and the concrete strength on their load-bearing capacity. For that purpose, the experimental program was designed as follows. All the beam-columns had the same round-ended rectangular cross-section whose dimensions are shown in Fig. 2. The section has a major axis length of $120 \mathrm{~mm}(\mathrm{~B})$ and a minor axis length of $50 \mathrm{~mm}$ (D). As a result, the cross-sectional aspect ratio $\mathrm{B} / \mathrm{D}$ is 2.4 which, according to Ding et al. [18], still is a low value of $\mathrm{B} / \mathrm{D}$ to assure the confining action from the steel tube to the concrete core.

In this program, the steel tube has a wall thickness of $2 \mathrm{~mm}$, quite close to those characterised as thin-walled, which gives a $\mathrm{D} / \mathrm{t}$ ratio of 25 in the rounded ends of the crosssection, Fig. 2. It should be noted that, in axially loaded members, the concrete contribution to the total capacity of the composite section with respect to the capacity of the hollow steel tube increases with a decrease in the steel tube thickness, although in this situation these tubes are more prone to suffer from local buckling. In addition, Hassanein and Patel [19] pointed out the necessity for more research on CFRT stub beam-columns with other values of D/t ratios since all the specimens tested to date had a $\mathrm{D} / \mathrm{t}$ ratio around 50 [18].

In total, 6 different load patterns were considered in agreement with the value of the load eccentricity $(0,5,10,20,25$ and $50 \mathrm{~mm})$. As can be seen, a concentrically loaded case was performed always as a reference ( $\mathrm{e}=0 \mathrm{~mm}$ ). According to the type of concrete placed in the steel tube, the specimens can be divided into two different series: series 1 with normal strength concrete of grade C30 and series 2 with high strength concrete of grade C90. Note that in the design of this research program, the focus was put on investigating the effect of HSC in 
the ultimate capacity and that the results of the NSC specimens were used to compare the trends.

In Table 1, the details of the specimens of both series are summarised. For convenience, the test specimens were named as follows: RND_F_E (i.e. RND_30_00), where RND stands for round-ended; F represents the nominal concrete strength in $\mathrm{MPa}$; and $\mathrm{E}$ is the load eccentricity in $\mathrm{mm}$.

All the specimens were manufactured and tested at the Universitat Jaume I in Castellón (Spain) in a horizontal testing frame with a capacity of $5000 \mathrm{kN}$. The test setup is presented in Fig. 3a. Eccentricity was applied over the major axis of the cross-section and with the same value at both ends (Fig. 3a and Fig. 3b). The tested stub beam-columns had a buckling length of $300 \mathrm{~mm}$ with pinned-pinned (P-P) boundary conditions. A steel plate with dimensions 300x300x10 mm was placed at both ends of each specimen.

\subsection{Materials properties}

\section{Concrete}

As commented in the previous section, two grades of nominal compressive strength were employed: C30 and C90. For each batch, the mix proportions are summarized in Table 2 and all of them are commercially available materials. In order to obtain the actual compressive strength $\left(f_{c}\right)$ which characterizes each concrete infill (presented in Table 1) the corresponding tests were carried out on the 150x300 mm cylinders. Therefore, in addition, sets of concrete samples were prepared and cured in standard conditions for 28 days until the test was performed. A planetary mixer was employed to prepare the mixes which were placed in the corresponding steel tubes and cylindrical moulds. A vibrator rod was employed to compact the concrete which was poured progressively into several layers. Later, the CFRT beam-columns were covered with wet clothes. To finish the preparation of the specimens, after one day of 
curing, the end surfaces were treated and prepared to ensure that both components acted when the load was applied. Fig. 3c shows a column ready to be tested.

Steel

In this campaign, all the specimens were obtained from the same cold formed steel hollow tube of nominal strength S275. Fig. 3d illustrates the preparation of the steel tubes. The actual yield strength was determined by the corresponding coupon tests ( 3 tests per tube) and a value of $306.98 \mathrm{MPa}$ was obtained. For the analysis, the modulus of elasticity of steel was set to $210 \mathrm{GPa}$ according to the European standards.

\section{TEST PROCEDURE AND RESULTS}

\subsection{Test procedure}

In the first place, the specimens were positioned horizontally in the testing frame (Fig. 3a) and correctly adjusted in order to ensure the proper application of the eccentric load. Next, the corresponding displacement control test was performed to ensure the accuracy of the measurements. The specimens were tested to failure and a displacement control protocol was used to properly register the post-peak response of the stub beam-columns, at least until the load reached back the $85 \%$ of its peak load in order to obtain enough experimental data for the posterior analysis. During the test, the imposed displacement rate was slow so that local buckling of the steel tube could be observed with precision. The procedure finished with the removal of the specimen, which was examined afterward.

\subsection{Maximum load}

The response of most of the specimens was relatively ductile and local buckling (outward folding) of the steel tube on the flat sides was observed together with crushing of concrete, both phenomena are typical failures of these types of composite columns, Fig. 4. 
The values of the experimental ultimate loads $\left(\mathrm{N}_{\exp }\right)$ were registered in every test and summarised in Table 1. Fig. 5 shows for both series- series 1 for NSC (C30) and series 2 for HSC (C90)- the maximum loads plotted versus the value of the eccentricity adopted in each experiment.

It can be observed in Fig. 5 that, as expected, the ultimate load decreases with an increase in the load eccentricity but there exists a clear change in the slope of the tendency line of the results. In this case, when the load eccentricity increases from 0 to $20 \mathrm{~mm}$, the ultimate load decreases up to $26 \%$ for both series. Nevertheless, for eccentricities higher than $20 \mathrm{~mm}$, the influence is much more moderate and the diminution of strength is less notable. In fact, when the load eccentricity varies from 20 to $50 \mathrm{~mm}$, the drop in the ultimate load is $6 \%$ for series $1 \mathrm{C} 30$ and $13 \%$ for series $2 \mathrm{C} 90$.

This analysis confirms that the grade of influence of the load eccentricity in the ultimate load is inherently linked to where the load application point lies within the CFRT cross-section. In those experiments in which the point lies within the rectangular part of the cross-section, where the steel tube walls are parallel, the beam-column is more sensitive to load eccentricity and the decrease in its strength is very notable. However, as the application point approximates the border between the rectangular and the rounded end, the compression is focused on this part and, thus, the effect of the hoop stresses appearing due to the composite action becomes more evident. This is due to the higher effectiveness of the confinement of the concrete core in circular sections than in rectangular shapes. This leads to a uniform distribution of lateral pressure in the rounded area which enhances the load-bearing capacity of the CFRT beamcolumn and prevents it from an abrupt loss of resistance, even with thin steel tubes. As commented previously, giving the value of the cross-sectional ratio of these specimens, the action of the confinement was expected to appear. 
As detailed above, the greater the eccentricity the greater the loss of strength. In this process, the concrete net area of the cross-section working under pure compression (which corresponds to its optimal performance) decreases. Nevertheless, it can be noticed that for series 2 C90 the reduction is higher than for series 1 C30, particularity for the $20-50 \mathrm{~mm}$ interval where the percentages of strength loss are $13 \%$ and $6 \%$ respectively. This fact corroborates that for HSC the confinement is less effective than for NSC, as already observed by the authors in previous research [6].

During the tests, the variation of the load along with the shortening of the column was registered and it is plotted in Fig. 6. For the sake of clarity, in the case of series 2 C90, only the most significant curves have been included. As can be observed in Fig. 6b, the ultimate capacity of the columns is clearly enhanced by the use of HSC and specimens with HSC show higher maximum loads. The influence of the concrete strength in the response of the columns is also reflected in the shape of the transition from the pre-peak to the post-peak. In the case of NSC columns, the transition is smooth contrarily to the sharp fall observed in HSC columns, due to the brittle character of HSC. Even for the specimens studied in this work, with relatively thin steel tubes, the confining action was noticeable and much more effective for NSC columns.

With respect to the influence of the load eccentricity, the post-peak branch becomes smoother with an increase in its value. This is more noticeable for specimens filled with HSC, Fig. 6b, which initially have a sharper post-peak. For higher values of eccentricity (in this case from $20 \mathrm{~mm}$ on), the cross-sectional stress state makes a substantial part of the steel tube work effectively under tension which enhances the ductile response of the stub beam-column.

\subsection{Strength Index}

In this study, a strength index (SI) is used to quantify the relation between the experimental ultimate load of a CFRT stub beam-column and its theoretical cross-sectional capacity under pure compression. It is defined as follows: 


$$
S I=\frac{N_{\text {exp }}}{A_{s} f_{y}+A_{c} f_{c}}
$$

where $\mathrm{N}_{\exp }$ is the experimental ultimate load, $\mathrm{A}_{\mathrm{s}}$ is the cross-sectional area of the steel tube, $\mathrm{f}_{\mathrm{y}}$ is the yield strength of the steel, $A_{c}$ is the cross-sectional concrete area and $f_{c}$ the cylindrical concrete strength.

For all the columns tested, the SI was calculated and the results are presented in Table 1 and in Fig. 7. It can be seen that only for the NSC concentrically loaded column, RND_30_00, the value of SI is slightly higher than one due to the confining action. The fact that even the column RND_90_00 has a SI less than one proves the poor composite response of the two components when HSC is employed. As expected, the rest of the specimens show a SI less than one and the value decreases with an increment in the load eccentricity. Again, the reduction of the SI is less pronounced for eccentricity range $20-50 \mathrm{~mm}$, where the failure is governed by the yielding of the steel tube.

\subsection{Concrete Contribution Ratio}

In a similar way, the contribution of the concrete infill was analysed for each specimen by the concrete contribution ratio (CCR) which can be calculated by:

$$
\text { CCR }=\frac{N_{\text {exp }}}{N_{\text {hollow, EC3 }}}
$$

where $\mathrm{N}_{\exp }$ is the experimental ultimate load and $\mathrm{N}_{\text {hollow,EC3 }}$ is the theoretical capacity of the hollow steel tube under eccentric loads according to Eurocode 3 (EC3) [22]. For these load conditions, eccentric compression, it is defined as:

$$
N_{\text {hollow }, E C 3}=\frac{f_{y}}{\frac{1}{A_{s}}+\frac{e}{W_{e l}}}
$$

where $A_{s}$ is the cross-sectional area of the steel tube, $f_{y}$ is the yield strength of the steel, e is the eccentricity and $\mathrm{W}_{\mathrm{el}}$ is the elastic section modulus. 
It is worthy to mention that Eurocode 3 design specifications do not cover the type of composite columns of this study, Fig. 2, but its guidelines are used for the calculation of the theoretical cross-sectional capacity. According to section 5.5.2 of EC3 [22], the round-ended hollow steel tube employed in this campaign can be classified for structural analysis as Class 3. That implies that it is a steel cross-section in which the stress in the extreme compression fibre, assuming an elastic distribution of stresses, can reach the yield strength. Only the development of the plastic moment resistance could be subjected to the appearance of local buckling.

The CCR values of the two series studied are summarised in Table 1 and plotted in Fig. 8. The results obtained corroborate the trend observed in Fig. 5 for the ultimate loads. As expected, the concrete infill contributes substantially to the load bearing capacity of CFRT beam-columns and the highest ratio of contribution is registered for the axially loaded columns. The CCR of specimen RND_30_00 is 2.15 which is more than twice the capacity of the roundended hollow steel tube. However, for column RND_90_00, the value of the CCR is 3.23, more than three times. As can be seen, the effect was more important in those columns with HSC, even with eccentric loads. As expected, when the load eccentricity increases, the CCR values tend to reduce. The part of the cross-section working under tension becomes gradually more significant and, under these circumstances, the concrete core is the critical component.

\subsection{Ductility Index}

A third ratio based on the load-axial shortening curves was employed for the analysis of the experimental results. This parameter is the ductility index (DI) and it is calculated as the inverse ratio between the axial shortening of the CFRT beam-column corresponding to the peak load $\left(\mathrm{N}_{\exp }\right)$ and the axial shortening corresponding to the point when it reaches back the $85 \%$ of the peak load $\left(\mathrm{N}_{\exp }\right)$ in the decay branch. In this work, as well as in previous works [6], the definition proposed by Han et al. [23] is adopted as suggested by other authors [24]: 


$$
D I=\frac{\delta_{85 \%}}{\delta}
$$

where $\delta$ is the axial shortening of the specimen corresponding to the peak load and $\delta_{85 \%}$ is the axial shortening when the load has fallen to the $85 \%$ of the peak load.

In Fig. 9, the extraction of the values required is shown schematically. In Fig. 9a, the pair of columns axially loaded (RND_30_00 and RND_90_00) are plotted while in Fig. 9b, the curve for the pair with load eccentricity of $20 \mathrm{~mm}$ are included (RND_30_20 and RND_90_20). It can be observed clearly in Fig. 9b how the post-peak branch is smoother for those beamcolumns with eccentric loads when compared to those in Fig. 9a.

The DI calculated values for the specimens tested are summarized Table 3. The higher the value of DI, the higher the ductility of the CFRT beam-columns since it means that the slope of the post-peak curve of the load-shortening curve is softer. As thought, CFRT beamcolumns with NSC had higher DI than those with HSC whose DI values are close to one. This concurs with the sharp transition peak in the response curves.

Given the stipulations of the devices utilised and the remarkably long duration of the experiments of the third pair of beam-columns (the two with load eccentricity of $50 \mathrm{~mm}$ ), the tests were interrupted before the specimens reached back the $85 \%$ of the peak load. Thus, although the parameter could not be calculated, this event shows their elevated ductility. 


\section{COMPARISON OF RESULTS WITH EUROCODE 4 PREDICTIONS}

In this section, the design resistances of the CFRT stub beam-columns were predicted using the specifications given by Eurocode 4 [21] and compared with the experimental values. Scarce references to the application of EC4 for CFRT columns can be found in the literature. Ding et al. [18], based on previous works by other authors, applied EC4 to assess the predictions of the numerical model developed, but only under axial compression. Particularly, for CFRT beam-columns subjected to eccentric loads no works can be detected.

It should be noted that, with the only aim of assessing the current method given by Eurocode 4, specimens of nominal strength C90 are also included although these are not covered by the code since this compressive strength is out of its applicability limits (25 $\left.\mathrm{MPa} \leq \mathrm{f}_{\mathrm{c}} \leq 50 \mathrm{MPa}\right)$

EC4 provides two design methods for CFST columns. In this case, given that the CFRT cross-section has double symmetry and is uniform over the member length, the simplified method can be applied. According to EC4, the cross-sectional resistance of a composite column subjected to combined compression and bending is determined from the bending moment versus axial force (M-N) interaction curve. Applying the simplified method (section 6.7.3.2), the $\mathrm{M}-\mathrm{N}$ interaction curve was obtained by scanning the CFRT cross-section along the major axis and calculating the points (A to D) corresponding to different stress distributions given by possible positions of the plastic neutral axis $\left(h_{n}\right)$ as shown schematically in Fig. 10. The initial and final points of the curve are defined as $\mathrm{N}_{\mathrm{pl}}$ and $\mathrm{M}_{\mathrm{pl}}$, respectively the plastic resistance under pure compression and the plastic moment resistance under pure bending for CFST beamcolumns without reinforcement. These can be calculated by:

$$
\begin{aligned}
& N_{p l}=A_{s} f_{y}+A_{c} f_{c} \\
& M_{p l}=f_{y}\left(W_{p a}-W_{p a n}\right)+0.5 f_{c}\left(W_{p c}-W_{p c n}\right)
\end{aligned}
$$


where $\mathrm{W}_{\mathrm{pa}}$ and $\mathrm{W}_{\mathrm{pc}}$ are the plastic section moduli for the steel and the concrete of the crosssection (assumed to be uncracked) respectively; and $\mathrm{W}_{\mathrm{pan}}$ and $\mathrm{W}_{\mathrm{pcn}}$ are the plastic section moduli of the corresponding components within the region of $2 \mathrm{~h}_{\mathrm{n}}$ around the horizontal symmetry axis of the composite cross-section, Fig. 10.

In summary, according to EC4 [21], the points A to D that define the simplified M-N interaction curve in Fig. 10 are given by:

- Point A: pure axial compression

$$
\begin{aligned}
& N_{A}=N_{p l} \\
& M_{A}=0
\end{aligned}
$$

- Point B: pure bending

$$
N_{B}=0
$$

$$
M_{B}=M_{p l}
$$

- Point C: bending and compression

$$
\begin{aligned}
& N_{C}=N_{p m}=A_{c} f_{c} \\
& M_{C}=M_{p l}
\end{aligned}
$$

- Point D: maximum moment resistance

$$
\begin{aligned}
& N_{D}=0.5 N_{p m}=0.5 A_{c} f_{c} \\
& M_{D}=M_{\text {max }}=W_{p a} f_{y}+0.5 W_{p c} f_{c}
\end{aligned}
$$

In Fig. 11, the M-N interaction curve for the cross-section of each series is plotted. Thus, two curves can be distinguished in function of the type of concrete infill: one for series $1 \mathrm{C} 30$ and another one for series 2 C90. In addition, the points corresponding to the experimental data are plotted for comparison. It can be observed that, for both series, the 
experimental points lie relatively close to the corresponding $\mathrm{M}-\mathrm{N}$ curve for load eccentricities up to $20 \mathrm{~mm}$. For higher eccentricities, the interaction diagram predicts a cross-sectional behaviour which differs greatly from the experimental results, being the code predictions quite conservative. This change on the behaviour is related, once more, with the part within the crosssection where the load is applied, as exposed in the previous section.

Regarding the type of infill, in the case of columns filled with NSC the EC4 underestimates the capacity, being all the tested points on the safe side of the interaction curve. On the contrary, for those columns filled with HSC, generally the EC4 slightly overestimates the load-bearing capacity for some columns filled with HSC. With regard to this, it must be noted again that the application of EC4 is limited to concrete with a maximum compressive strength of $50 \mathrm{MPa}$, so the particular behaviour of HSC is not taken into account.

Once the $\mathrm{M}-\mathrm{N}$ interaction diagram has been built, the predicted values $\left(\mathrm{N}_{\mathrm{EC} 4}\right)$ are obtained from the intersection of the M-N curve with the line given by the load eccentricity in each case. This can be observed in Fig. 11, where the dotted lines correspond to the different eccentricities considered.

In Fig. 12, the comparison between the experimental ultimate loads and the predictions given by EC4 ( $\left.\mathrm{NEC}_{\mathrm{E}}\right)$ for each eccentricity analysed is shown. This graph corroborates that EC4 predictions are mostly accurate, except for the larger eccentricities. The results obtained are also summarized in Table 4, $\mathrm{N}_{\mathrm{EC} 4}$, together with the error calculated with respect to the experimental values, $\mathrm{N}_{\exp } / \mathrm{N}_{\mathrm{EC} 4}$ (mean error on safe side 1.13). In general, the error lies inside the $\pm 10 \%$ boundaries. Note that for the case of HSC with a load eccentricity of $50 \mathrm{~mm}$, RND_90_50, the test ultimate load is a 57\% higher than that predicted by EC4. 


\section{EQUIVALENT RECTANGULAR CFST CROSS-SECTION APPROACH}

As exposed before, Eurocode 4 does not include CFRT geometry among its range of application. Regardless, when the EC4 guidelines are applied to predict the response of this type of columns the cross-sectional properties need to be obtained, which for practitioners can be a tedious task on their daily work in the case of this novel sections. Working in this line, it is possible to take a step forward to set the basis of an approach based on an equivalent rectangular CFST cross-section, shape covered by EC4, which leads to the same response that the corresponding CFRT beam-column.

It should be noted that the proposal described in this section it is just a preliminary approach developed with a very limited number of experiments, not sufficient for the creation of a new interaction diagram. For the development and validation of an interaction diagram more data will be needed, from both experiments and validated models able to capture the response of the columns. Therefore, the predictions obtained and its comparison with the EC4 diagram should then be taken with caution.

The rectangular shape is the one selected for this approach, based on the structural advantage related to having different major and minor axis properties, a characteristic also owned by round-ended cross-sections. However, this geometry, as a result of its simple crosssectional properties, would facilitate architects and engineers the use of CFRT columns in their designs. Moreover, as reported by Ding et al. [18], in previous works other authors tried to predict the capacity of CFRT columns by applying simple models that were developed for rectangular shapes.

A starting point could be the adoption of a rectangular section that, maintaining the values of the minor axis length (D) and the steel tube thickness (t), has a major axis length equal to the plane part of the CFRT cross-section. This proposal is conservative given the 
proven positive effect of the rounded ends of the cross-section. This equivalent cross-section is shown in Fig. 13a and the dimension $\mathrm{B}_{0}$ is given by:

$$
B_{0}=B-D
$$

According to EC4, the predicted strengths and the M-N interaction curves have been calculated for this first proposal, hereafter proposal $\mathrm{B}_{0}$, and compared with the values obtained by means of the laboratory tests. These curves are represented for series 1 and series 2 in Fig. 14a and in Fig. 14b respectively. As expected, the predictions are too conservative even for small load eccentricities but implementing proposal $\mathrm{B}_{0}$ permits to estimate of the influence of the rounded ends in the cross-sectional resistance.

Again, in Table 4 the predicted capacities $\left(\mathrm{N}_{\text {eq-B0}}\right)$ and the error are summarized. The error calculated as the relation $\left(\mathrm{N}_{\exp } / \mathrm{N}_{\text {eq- }} \mathrm{B} 0\right)$ is plotted in Fig. 15. In this case, the mean error lies on the safe side with a value of 1.51. As explained above, the procedure to obtain $\mathrm{N}_{\text {eq- }} \mathrm{B} 0$ is based in the intersection point between the line given by the eccentricity and the M-N curve.

After these results, another attempt was done to include the effect of the rounded ends in the cross-section response. Thus, in a second attempt, the focus was set on finding an equivalent rectangular cross-section in which the centre of gravity of each half of the crosssection matched the position of the centre of gravity of each half of the corresponding CFRT cross-section. This is linked with the important rule that this parameter has in the determination of the M-N interaction curve in the EC4 design rules. Thus, a second proposal is made where the length of the major axis of the equivalent rectangular CFST cross-section is defined by:

$$
B_{1}=B-D+\frac{4}{3 \pi}(D-2 t)
$$

In this proposal, hereafter proposal $\mathrm{B}_{1}$, the dimensions of the minor axis length (D) and the steel tube thickness ( $\mathrm{t}$ ) are also equal to those of the original CFRT cross-section. As 
derived, the total cross-sectional area is different from that of the original shape, being this one of the possible limitations of this approach.

The M-N interaction curves obtained for proposal $\mathrm{B}_{1}$ are plotted in Fig. 14a and in Fig. $14 \mathrm{~b}$ for series $1, \mathrm{NSC}$, and 2, HSC, respectively. This prediction can be compared with the curves obtained previously for proposal $\mathrm{B}_{0}$ and for the original CFRT cross-section. Besides, the experimental values are shown as dots. It can be observed that the shape described by the $\mathrm{M}-\mathrm{N}$ curve given by proposal $\mathrm{B}_{1}$ differs greatly from that of the proposal $\mathrm{B}_{0}$ and that is closer to the CFRT curve in the initial part. The most substantial change is observed at the final part of the curve, for load eccentricities higher than $20 \mathrm{~mm}$. In this region, the curve $\mathrm{B}_{1}$ extends more to the right part of the diagram covering also the area where the points corresponding to higher load eccentricities lie.

It can be seen in Fig. 14 that, for both series, NSC and HSC, the proposal $\mathrm{B}_{1}$ generally improves its accuracy in the prediction of the responses. Although it is observed that for low eccentricities, the curve $\mathrm{B}_{1}$ gets away from the experimental points and becomes safer, accuracy is significantly enhanced in the high eccentricities part. Thus, it is a compromise solution between the two different regions that allow to obtain more precise but still safe design resistances.

In Table 4 , the predictions given by proposal $\mathrm{B}_{1}$ are presented $\left(\mathrm{N}_{\mathrm{eq}-\mathrm{B} 1}\right)$ and also the error obtained with respect to the tests values $\left(\mathrm{N}_{\text {exp }} / \mathrm{N}_{\text {eq-B1 }}\right)$. To obtain the predictions given by this approach $\left(\mathrm{N}_{\mathrm{eq}-\mathrm{B} 1}\right)$, once more, the intersection points between the eccentricity lines and the M$\mathrm{N}$ curve are calculated. The graphical representation of this data is displayed in Fig. 16 where the tendency to produce safe results can be observed (mean error 1.14) and also that, even those points lying on the unsafe side, are inside the $10 \%$ boundary. When compared to the original CFRT curve, it can be seen that the mean value of the predictions given by both approaches is 
practically the same. However, it can be noted that the dispersion has decreased (SD 0.13 versus the initial SD 0.27), Table 4.

According to the obtained results, it can be said that a new, more accurate, approach based on an equivalent rectangular CFST cross-section can be found to calculate the design loads of CFRT stub beam-columns according to EC4 methods. However, this is obviously only an initial approach and more studies need to be done in this line to extend the validity of the proposal to another type of CFRT cross-sections.

\section{CONCLUSIONS}

The results of an experimental campaign on 9 concrete-filled round-ended steel tubular (CFRT) stub beam-columns subjected to eccentric loads are presented in this paper. The specimens were filled with two types of concrete infill (NSC and HSC). From the tests, the response in terms of load versus column shortening was obtained. Based on the experimental results, several parameters were used for the analysis of the influence of the concrete infill, the composite action and the level of ductility. Next, the Eurocode 4 method to predict the resistance of these columns was assessed and, finally, a new approach based on an equivalent rectangular CFST cross-section was presented and analysed. Thus, from this study several aspects are worth noting:

- There is a lack of experimental studies on CFRT beam-columns, particularly subjected to eccentric loads and filled with HSC.

- The response of most of the specimens was generally ductile and local buckling of the steel tube was observed together with crushing of concrete.

- The ultimate load is inversely proportional to the load eccentricity but the magnitude of the effect depends on the region of the cross-section where the load is applied. When the application point lies on the rounded part, the confinement is more effective and the 
response is dominated by the yielding of the steel tube. This prevents the beam-column from suffering a severe loss of resistance.

- CFRT beam-columns with HSC shown the highest maximum loads. CCR values evidenced the efficiency of HSC as infill, especially for low load eccentricities.

- As expected, a more ductile response was observed for beam-columns with NSC with a smooth decay branch in the response curve. DI values for HSC are lower, corresponding to a curve with an abrupt transition. Besides, for each series studied, the DI is higher for those under eccentric loads, due to the effect of the steel tube.

- EC4 overestimates the failure loads of the CFRT specimens filled with HSC subjected to low load eccentricities (in this particular case up to $20 \mathrm{~mm}$ ). For higher eccentricities, there is a tendency to produce unsafe predictions. An approach based on an equivalent rectangular CFST cross-section was presented for the CFRT cross-section studied.

In view of the results, further tests and studies are needed for evaluating the actual accuracy of the code in predicting the capacity of CFRT stub beam-columns with different cross-sectional aspect ratios and concrete grade infills.

The continuation of this work could be also supported by a corresponding numerical model which, properly calibrated and validated, would be able to simulate the behaviour of the CFRT beam-columns considering the variation of the parameters studied. That would help to generate an extensive database of results to validate new methods and to design future experimental programs in an optimal manner.

\section{ACKNOWLEDGEMENTS}

The authors would like to express their sincere gratitude to the Generalitat Valenciana for the project (GV/2015/098), entitled "Análisis numérico de la configuración óptima y sostenible de pilares mixtos tipo concrete filled steel tubes (CFT)". 


\section{REFERENCES}

[1] Zhao XL, Han LH, Lu H. Concrete-filled tubular members, 1st Ed. Oxon: Spon Press; 2010.

[2] Hernández-Figueirido D, Piquer A, Portolés JM, Hospitaler A, Montalvá JM. Optimal economic design of unprotected circular concrete-filled steel tubular at ambient temperature and under fire condition. 15th International Symposium on Tubular Structures. Brasil 2015; 175-180.

[3] Schneider SP. Axially loaded concrete-filled steel tubes. Journal of Structural Engineering 1998; 124(10): 1125-1138.

[4] Goode D. Composite columns - 1819 tests on concrete-filled steel tube columns compared with Eurocode 4. The Structural Engineer 2008; 86 (16).

[5] Shanmugam NE, Lakshmi B. State of the art report on steel-concrete composite columns. Journal of Constructional Steel Research 2001; 57(10): 1041-1080.

[6] Ibañez C, Hernández-Figueirido D, Piquer A. Shape effect on axially loaded high strength CFST stub columns. Journal of Constructional Steel Research, 2018;147: 247-256.

[7] Bradford MA, Roufegarinejad A. Elastic local buckling of thin-walled elliptical tubes containing elastic infill material. Interaction and Multiscale Mechanics 2007; 1(1):143156.

[8] Dai X, Lam D. Numerical modelling of axial compressive behaviour of short concretefilled elliptical steel columns. Journal of Constructional Steel Research 2010; 66 (7): 931942.

[9] Yang H, Lam D, Gardner L. Testing and analysis of concrete-filled elliptical hollow sections. Engineering Structures 2008; 30(12): 3771-3781.

[10] Zhao XL and Packer JA. Tests and design of concrete filled elliptical hollow section stub columns. Thin-Walled Structures 2009; 47(6-7): 617-628. 
[11] Jamaluddin N, Lam D, Dai XH, Ye J. An experimental study on elliptical concrete filled columns under axial compression. Journal of Constructional Steel Research 2013; 87: 616.

[12] Ren QX, Han LH, Lam D, Li W. Tests on elliptical concrete filled steel tubular (CFST) beams and columns. Journal of Constructional Steel Research 2014; 99: 149-160.

[13] Uenaka K. Experimental study on concrete filled elliptical/oval steel tubular stub columns under compression. Thin-Walled Structures 2014; 78:131-137.

[14] Chan TM, Gardner L, Law KH. Structural design of elliptical hollow sections: a review. Structures and Buildings 2010; 163 (6):391-402.

[15] Sheehan T, Dai XH, Chan TM, Lam D. Structural response of concrete-filled elliptical steel hollow sections under eccentric compression. Engineering Structures 2012; 45: 314-323.

[16] Zhu JH, Young B. Cold-formed-steel oval hollow sections under axial compression. Journal of Structural Engineering 2011; 137(7): 719-727.

[17] Zhu JH, Young B. Design of cold-formed steel oval hollow section columns. Journal of Constructional Steel Research 2012; 71: 26-37.

[18] Ding F, Fu L, Yu Z, Li G. Mechanical performances of concrete-filled steel tubular stub columns with round ends under axial loading. Thin-Walled Structures 2015; 97: 22-34.

[19] Hassanein MF, Patel VI. Round-ended rectangular concrete-filled steel tubular short columns: FE investigation under axial compression. Journal of Constructional Steel Research 2018; 140: 222-236.

[20] Han KH, Ren QX, Li W. Tests on stub stainless steel-concrete-carbon steel double-skin tubular (DST) columns. Journal of Constructional Steel Research 2011; 67: 437-452. 
[21] CEN EN 1994-1-1. Eurocode 4: Design of composite steel and concrete structures. Part 11: General rules and rules for buildings. Brussels, Belgium: Comité Européen de Normalisation; 2004

[22] CEN EN 1993-1-1. Eurocode 3: Design of steel structures. Part 1.1: General rules and rules for buildings. Brussels, Belgium: Comité Européen de Normalisation; 2005.

[23] Han LH, Zhao XL, Tao Z. Tests and mechanics model for concrete filled SHS stub columns, columns and beam-columns. Steel \& Composite Structures - An International Journal 2001; 1(1): 51-74.

[24] Han LH. Tests on stub columns of concrete-filled RHS sections. Journal of Constructional Steel Research 2002; 58 (3):353-372. 
a)

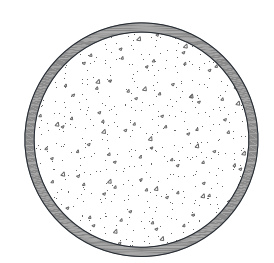

c)

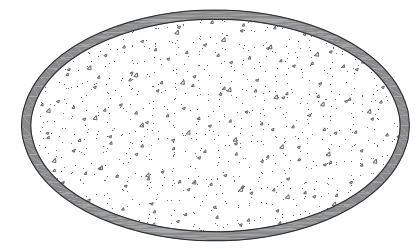

b)

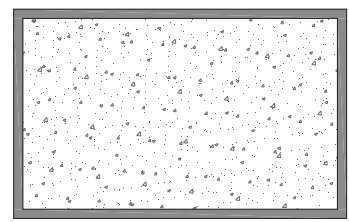

d)

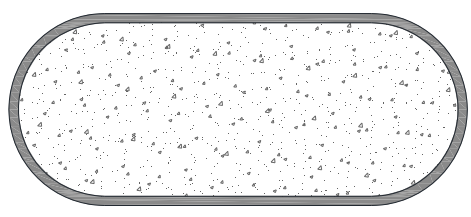

Fig. 1. Different cross-sectional shapes for CFST columns: a) Circular; b) Rectangular; c) Elliptical; d) Round-ended.

a)

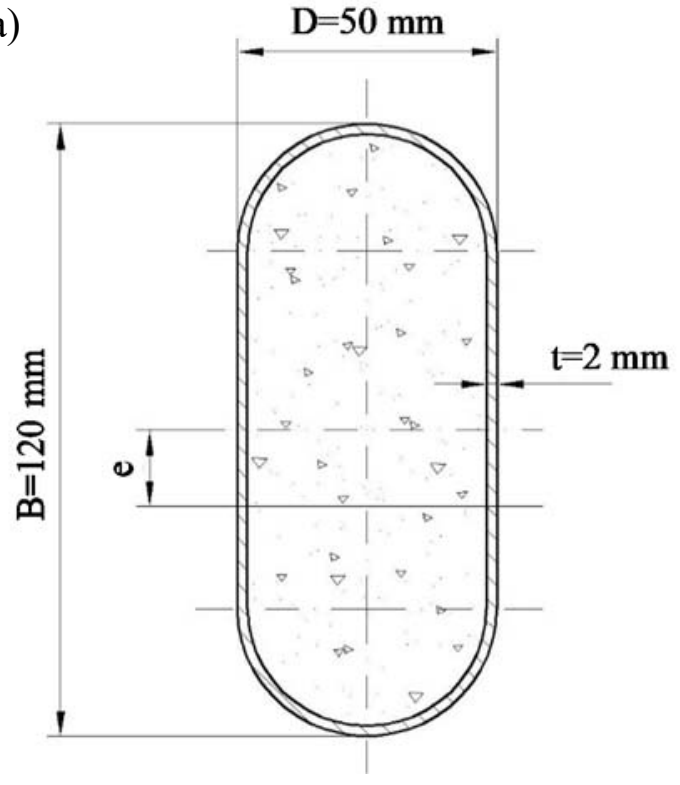

b)

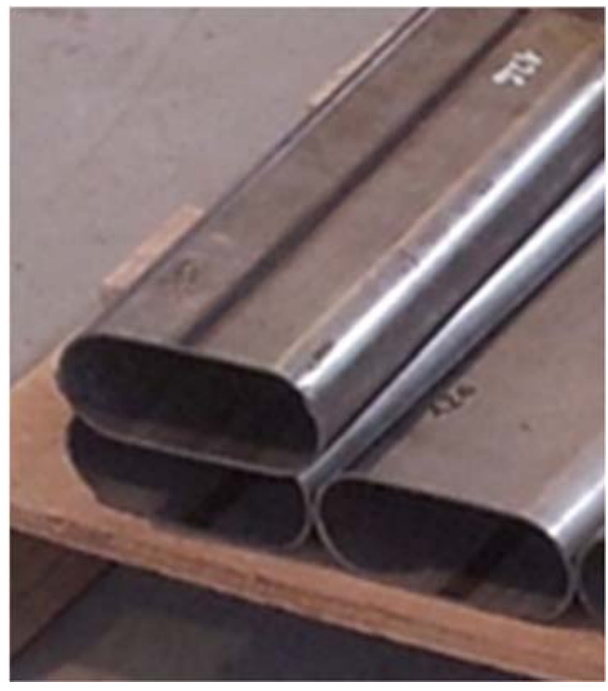

Fig. 2. Column cross-section: a) Dimensions; b) Round-ended hollow steel sections. 
a)

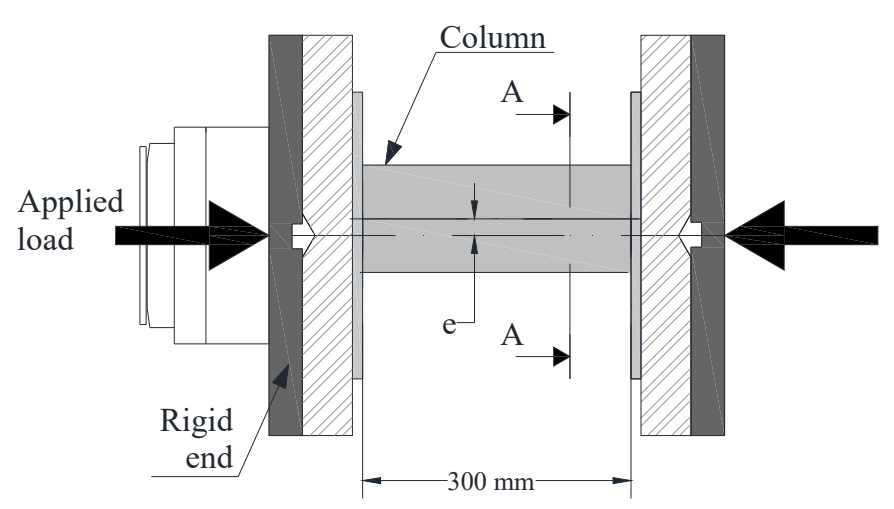

Section A-A

b)

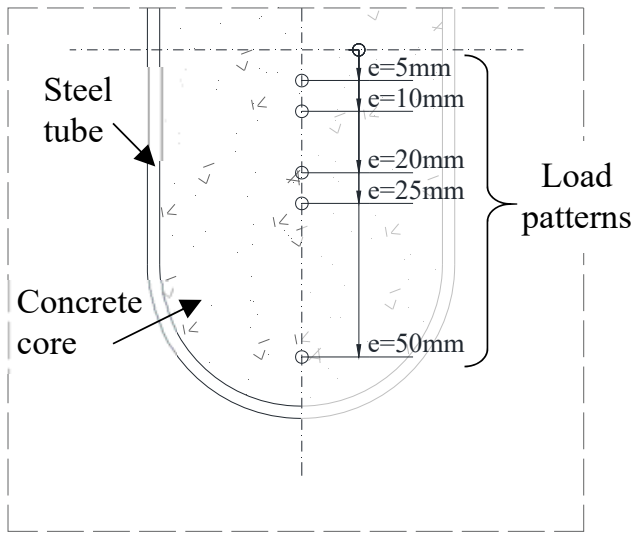

$\operatorname{Detail} A$

c)

d)

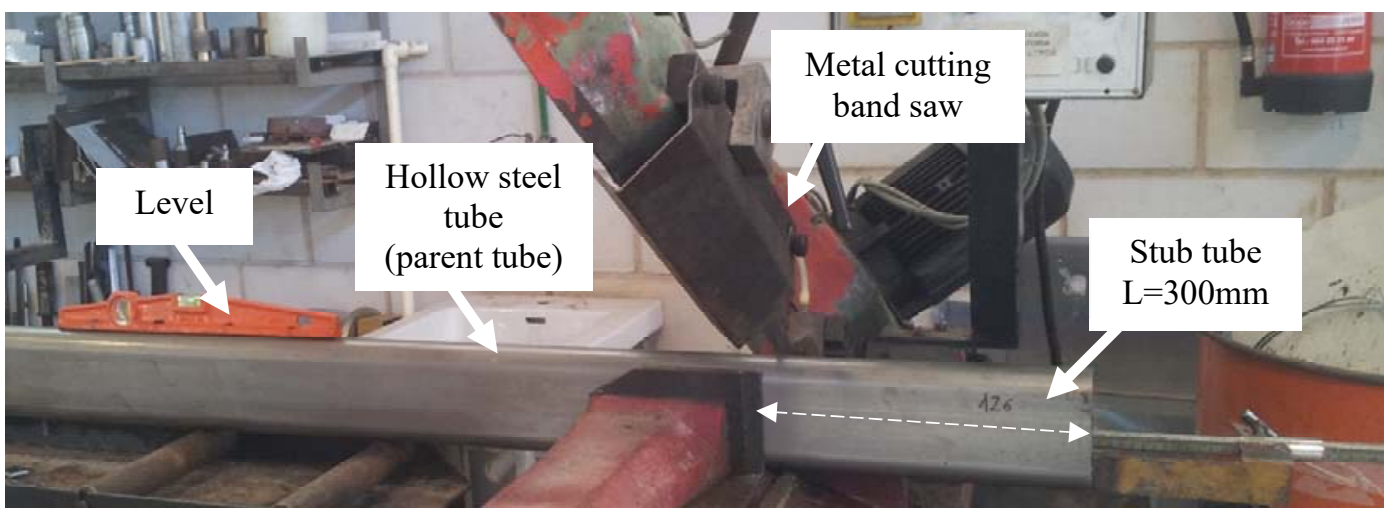

Fig. 3. Test setup: a) Schematic view; b) Detail of load patterns; c) CFRT stub beamcolumn ready to be tested; d) Preparation of the steel tubes. 


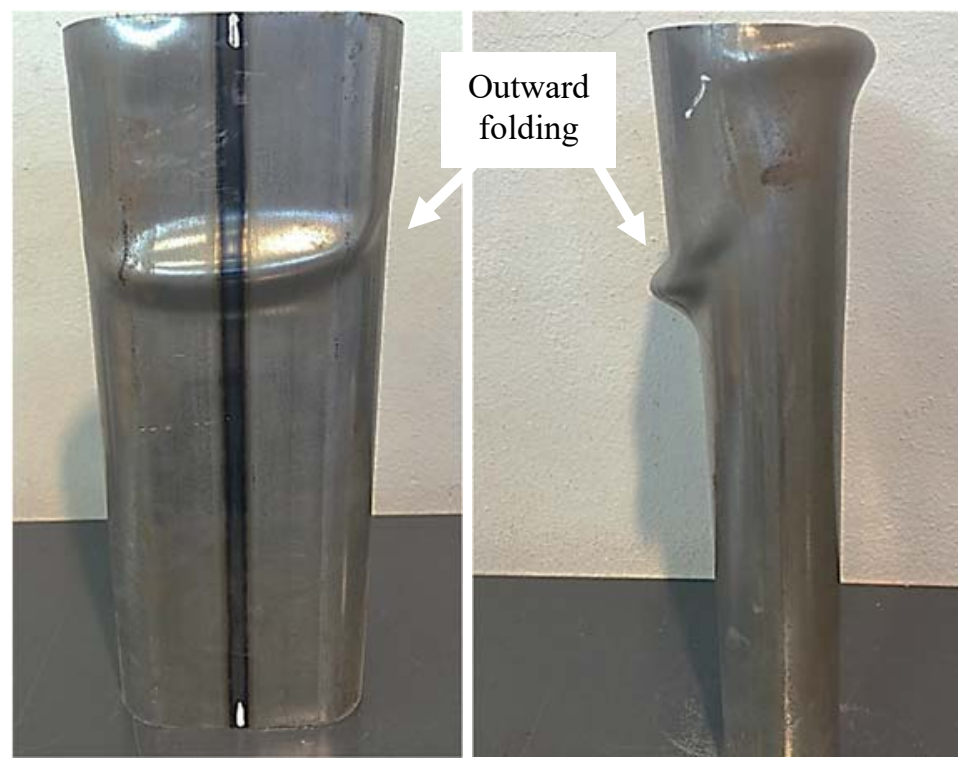

Fig. 4. Typical failure mode.

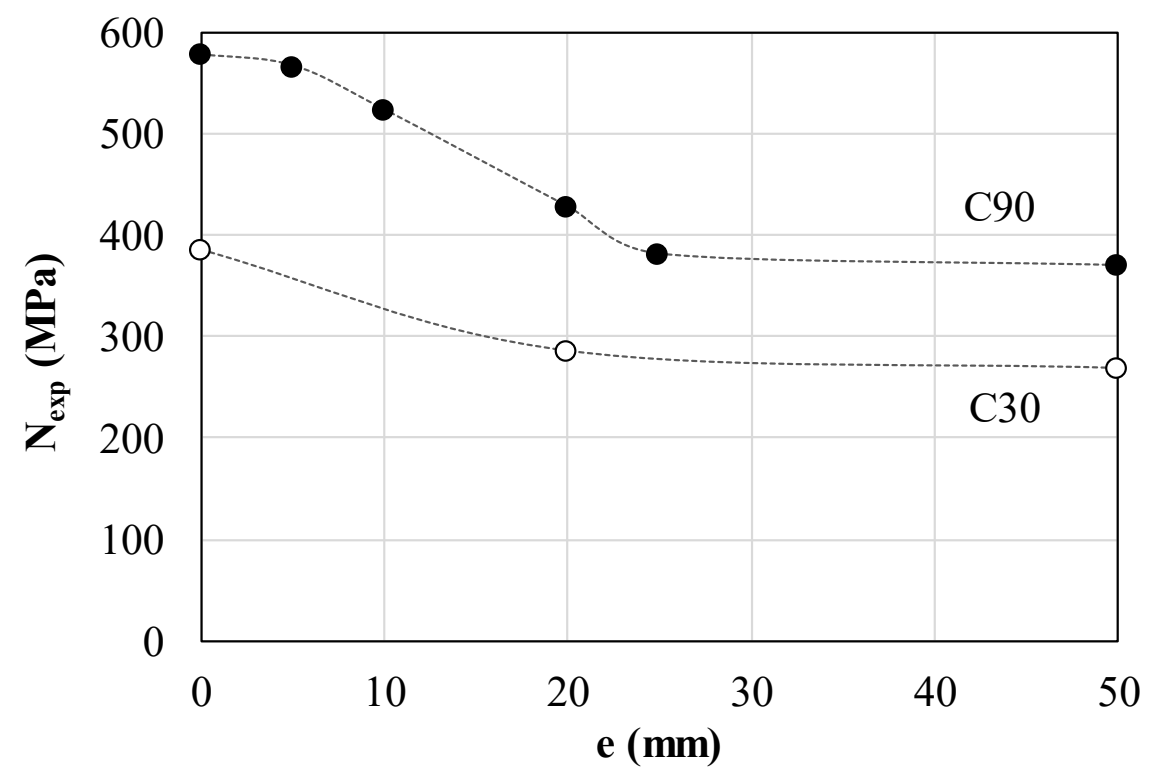

Fig. 5. Ultimate load vs eccentricity. 
a)

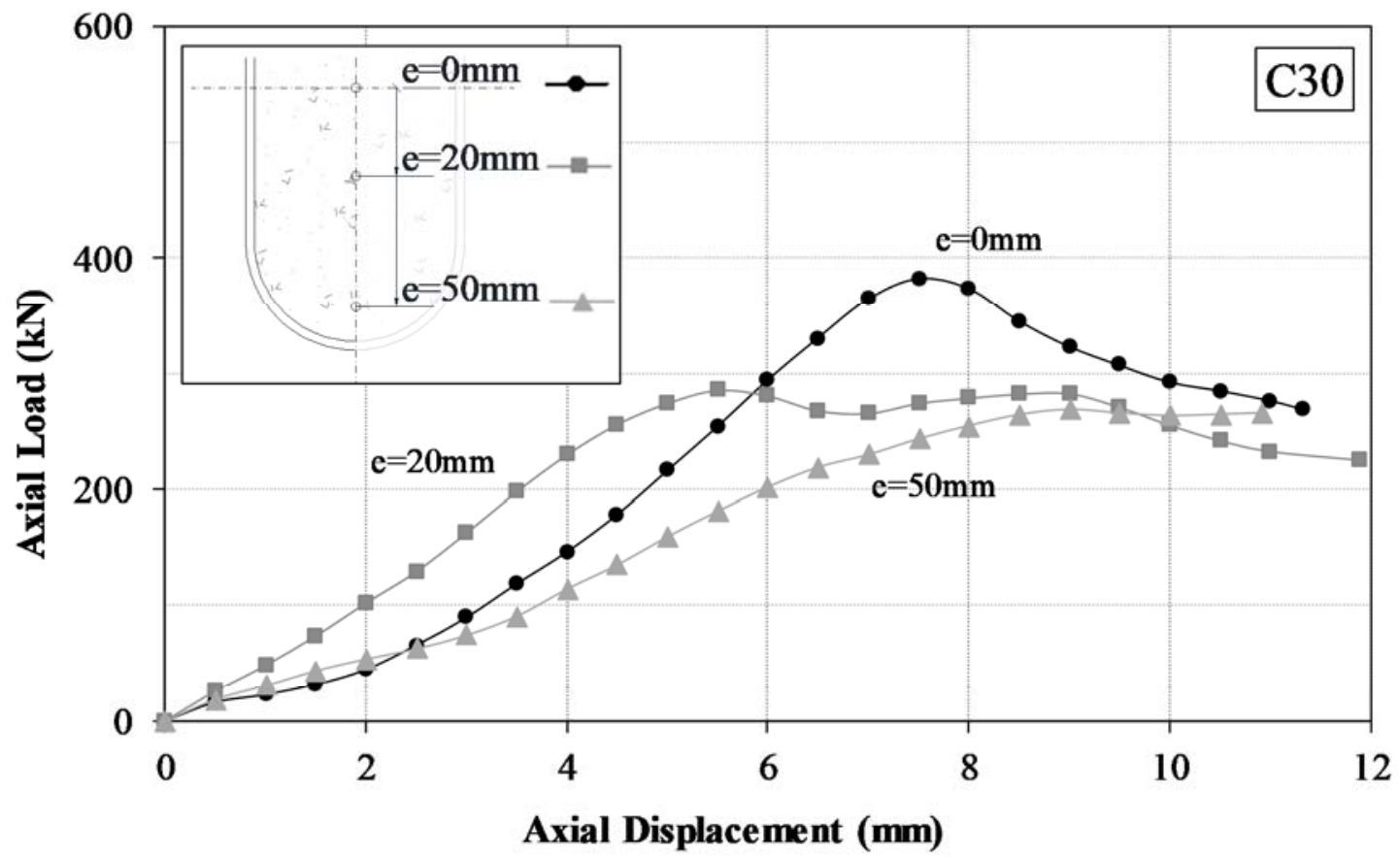

b)

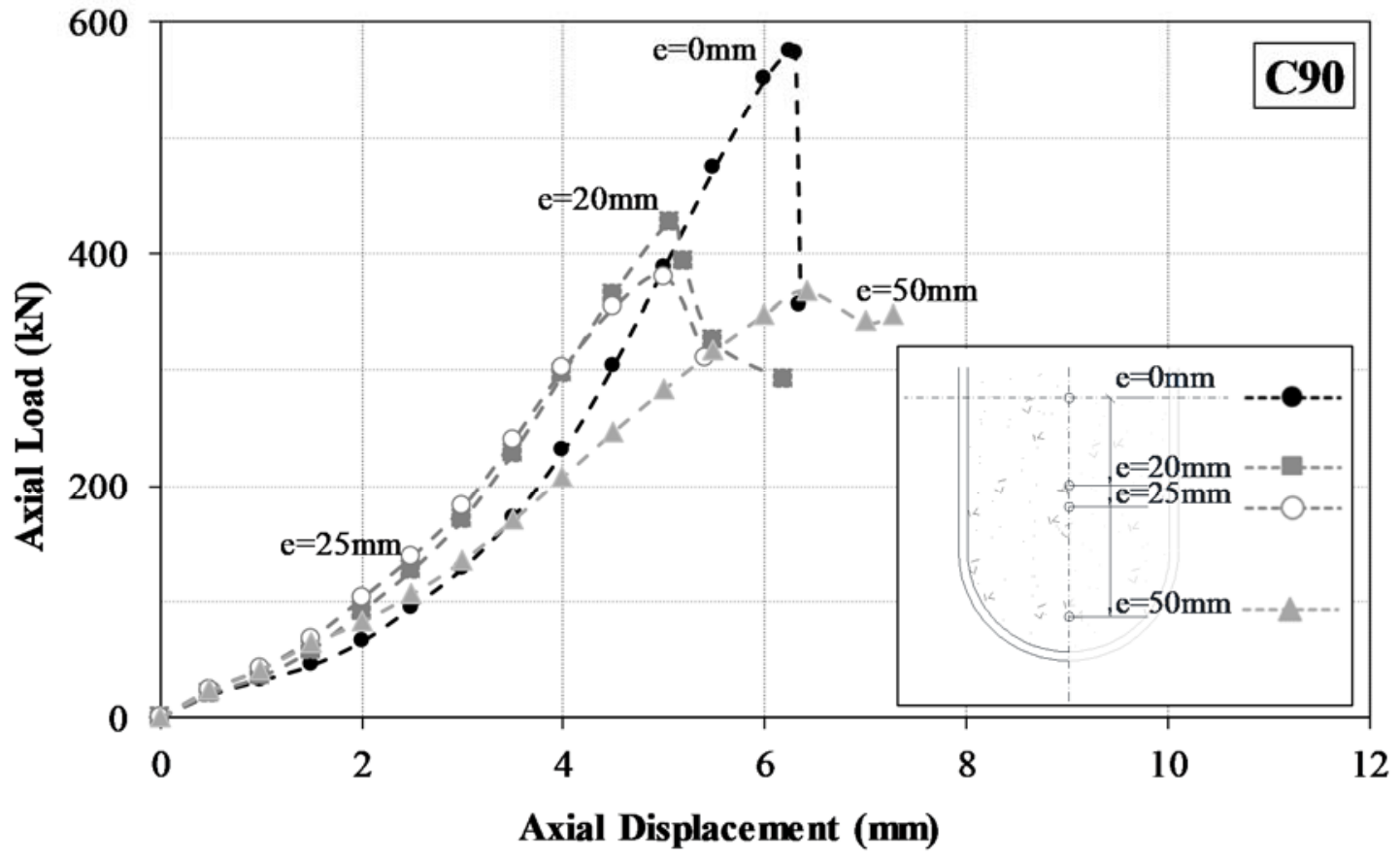

Fig. 6. Compression load versus shortening for: a) Series 1 C30; b) Series 2 C90. 
Piquer A., Ibañez C., Hernández-Figueirido D. Structural response of concrete-filled round-ended stub columns subjected to eccentric loads. Engineering Structures 2019; 184: 318-328

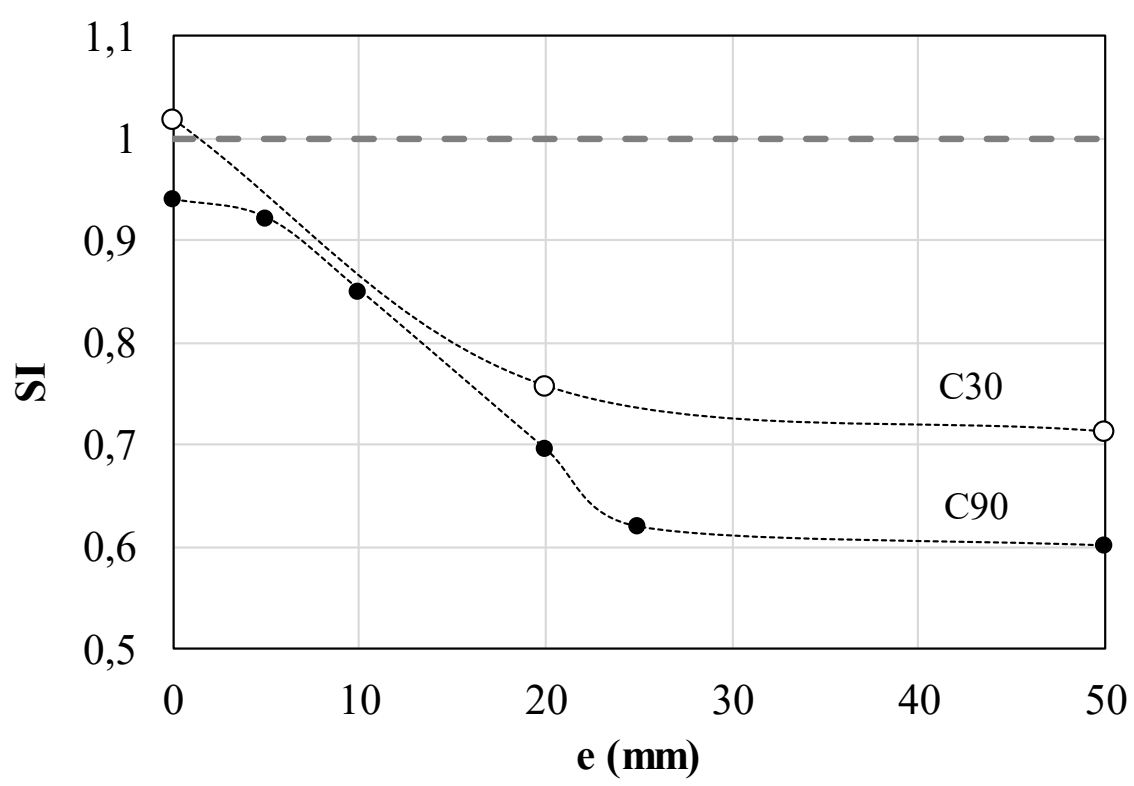

Fig. 7. Strength index (SI) vs eccentricity.

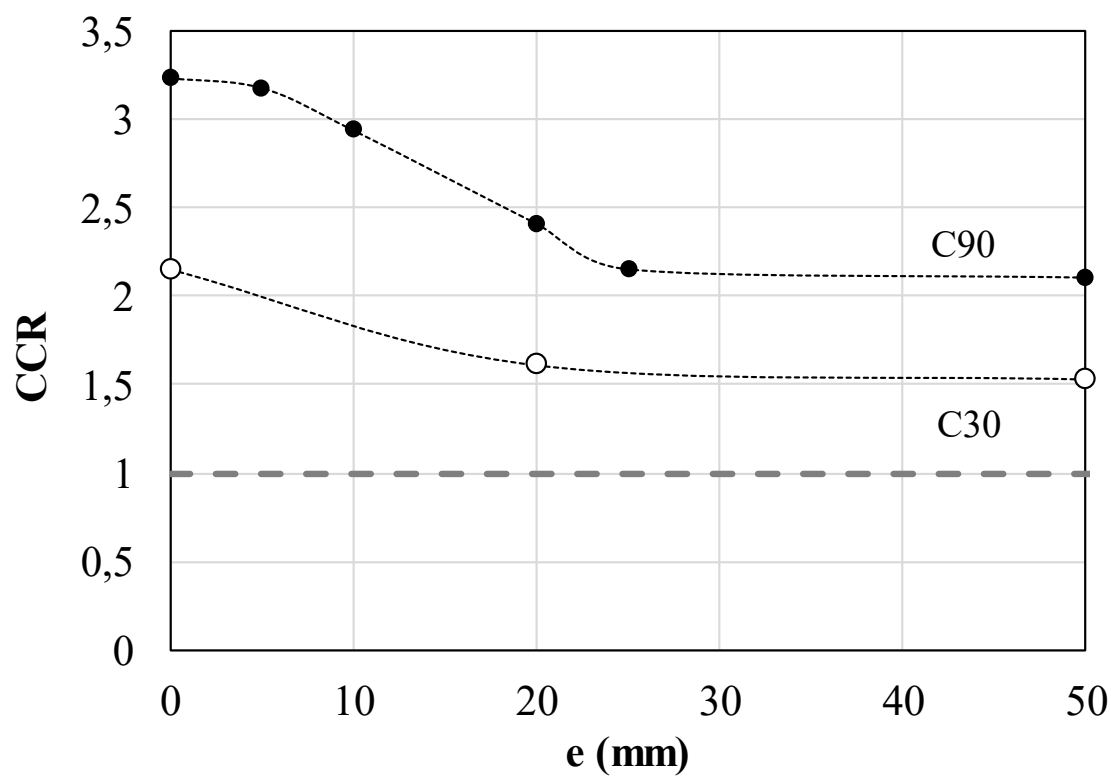

Fig. 8. Concrete contribution ratio (CCR) vs eccentricity. 
a)

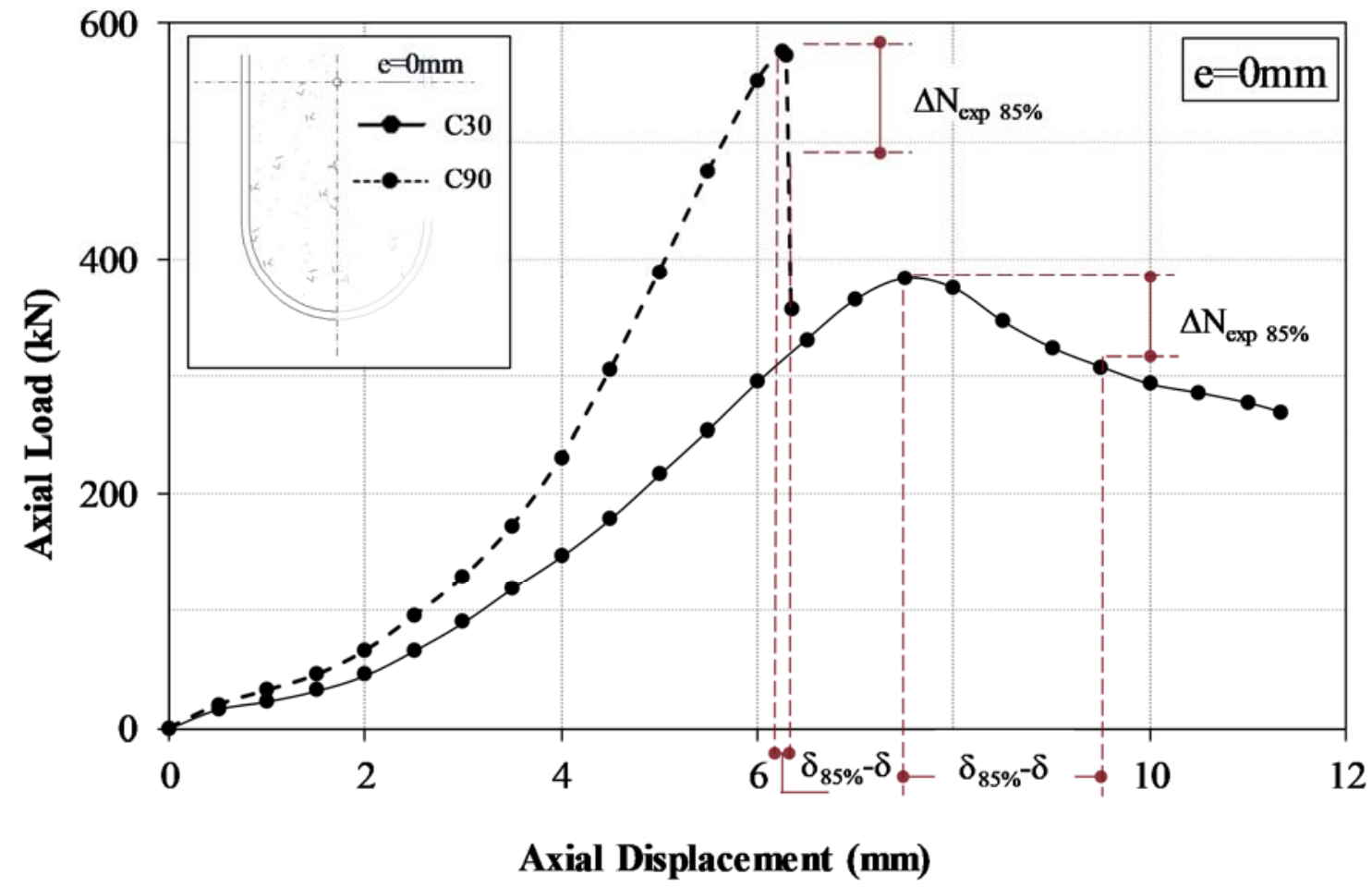

b)

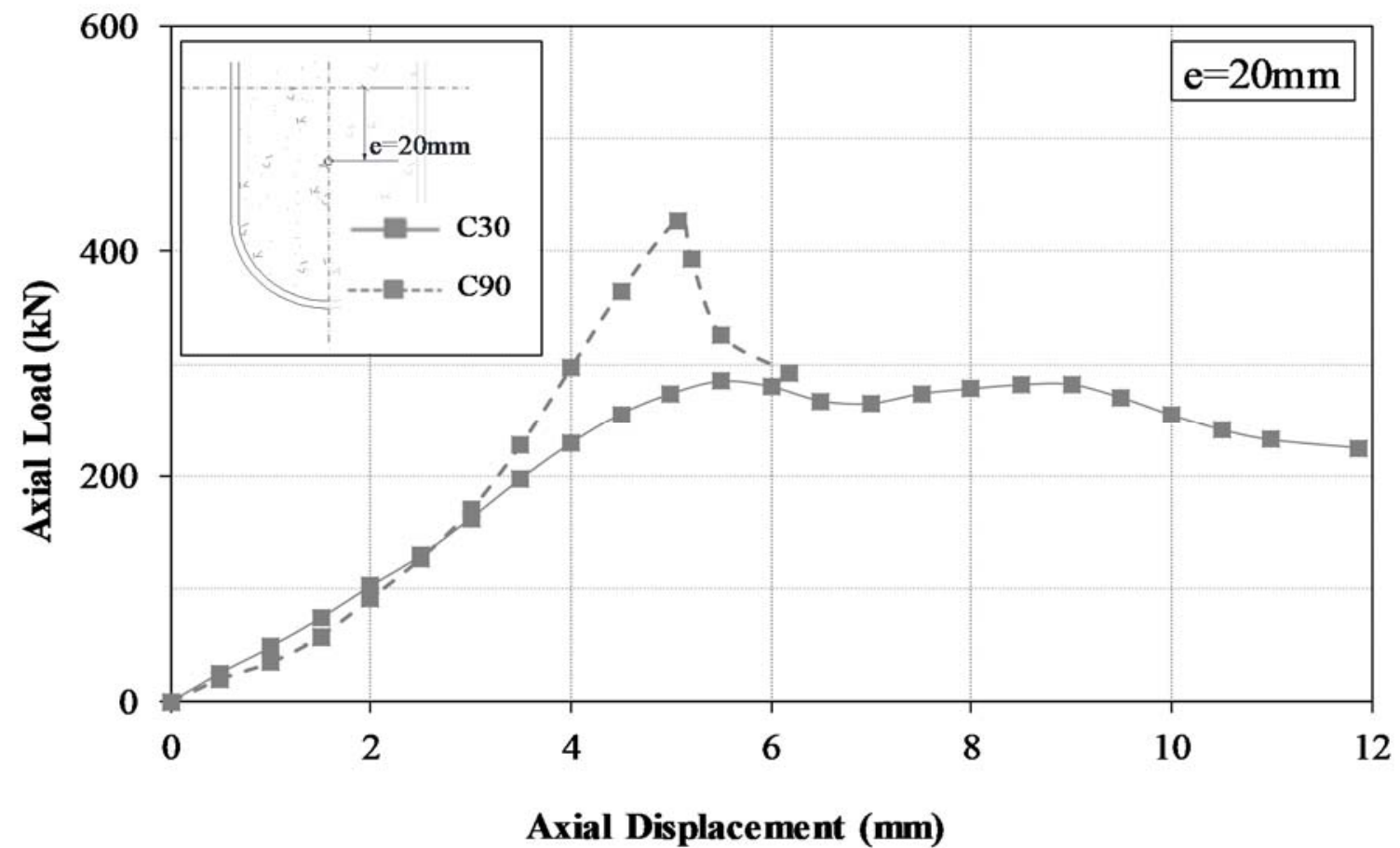

Fig. 9. Determination of ductility index from load-shortening curves: a) Columns RND_30_00 and RND_90_00; b) Columns RND_30_20 and RND_90_20. 


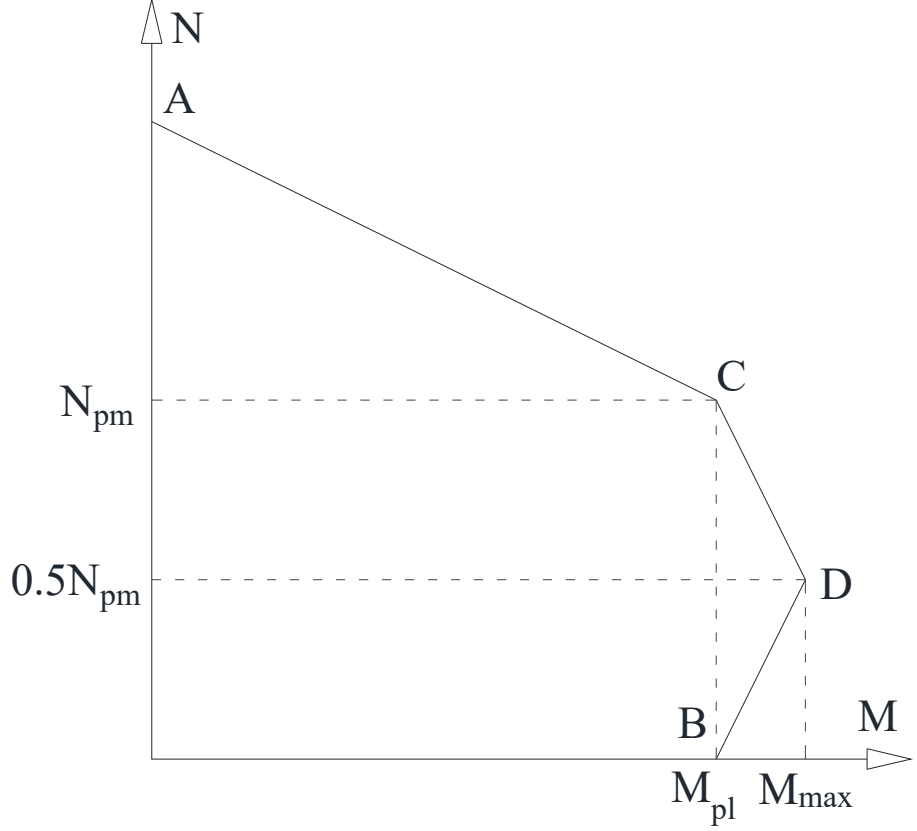

A

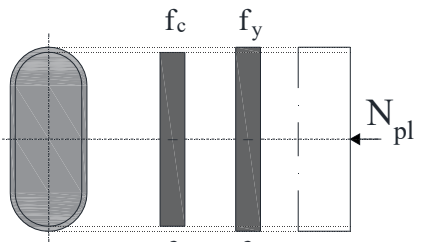

B

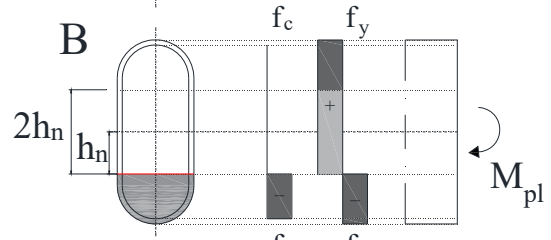

$\mathrm{C}$ $f_{c} \quad f_{y}$

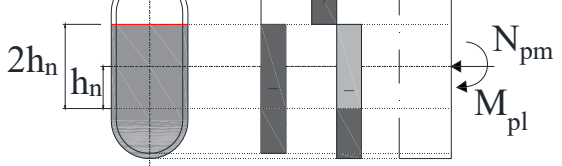

$\mathrm{D}$

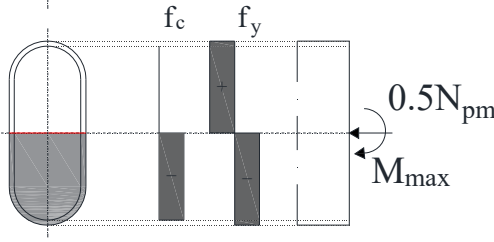

Fig. 10. M-N interaction curve determination according to EC4.

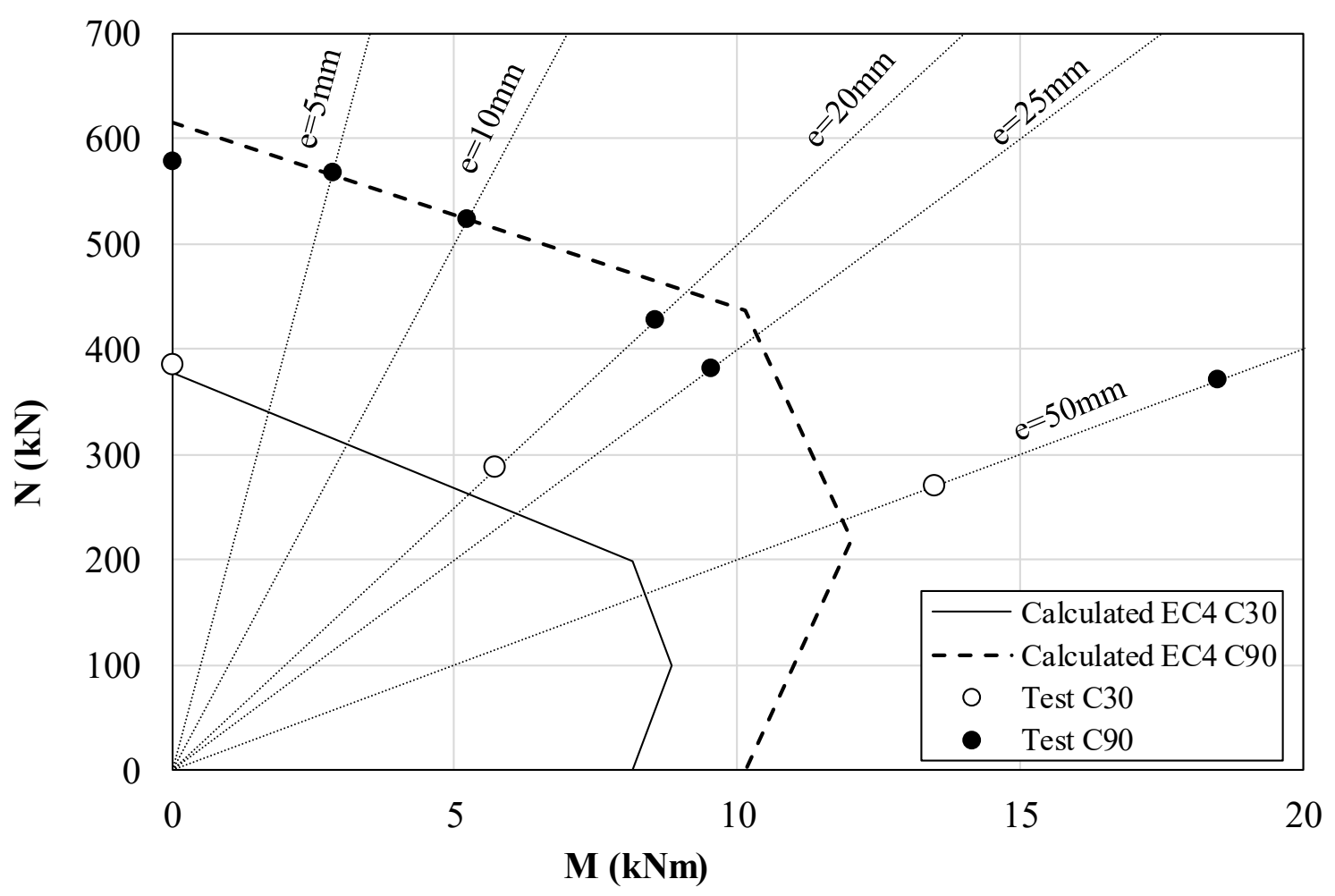

Fig. 11. Combined axial force-bending moment $\mathrm{M}-\mathrm{N}$ interaction curve. 


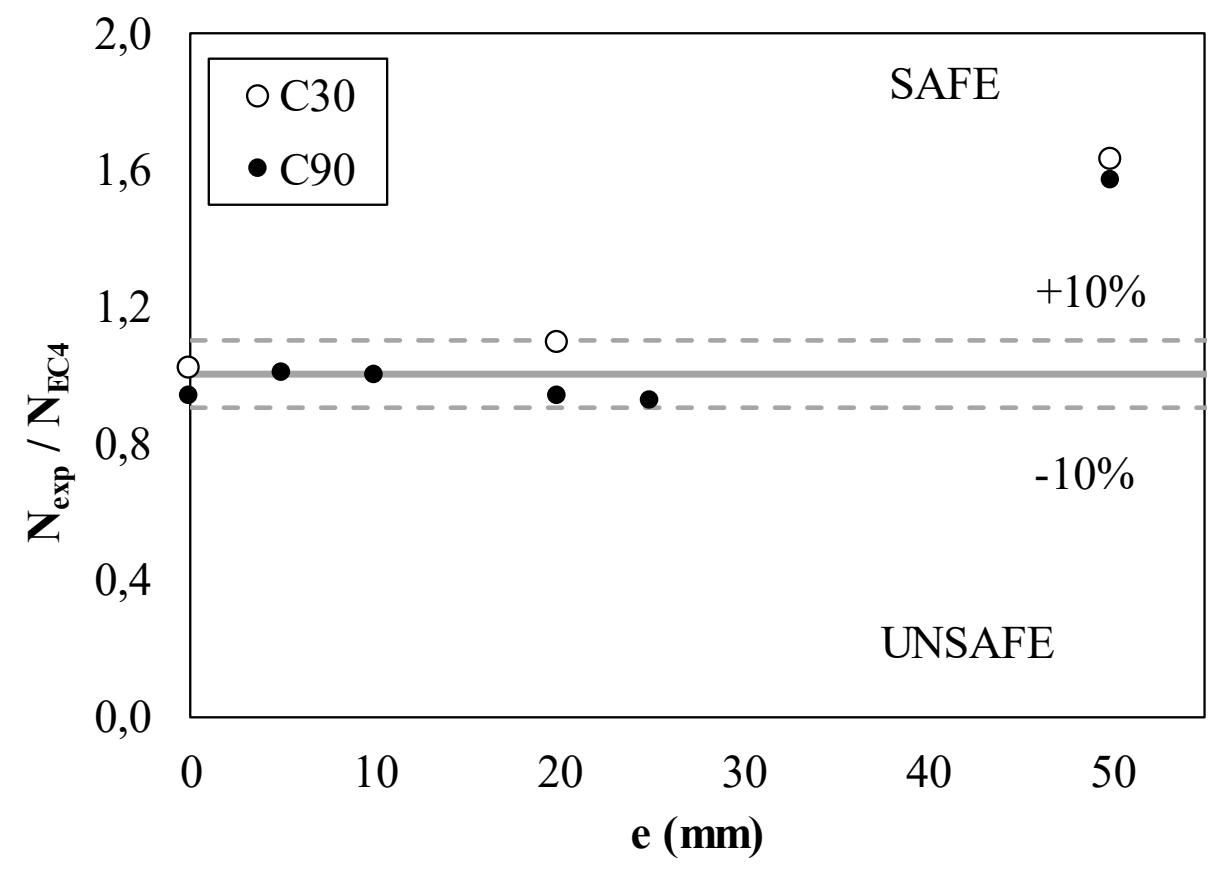

Fig. 12. Comparison between EC4 predictions and measured cross-sectional strengths.

a)

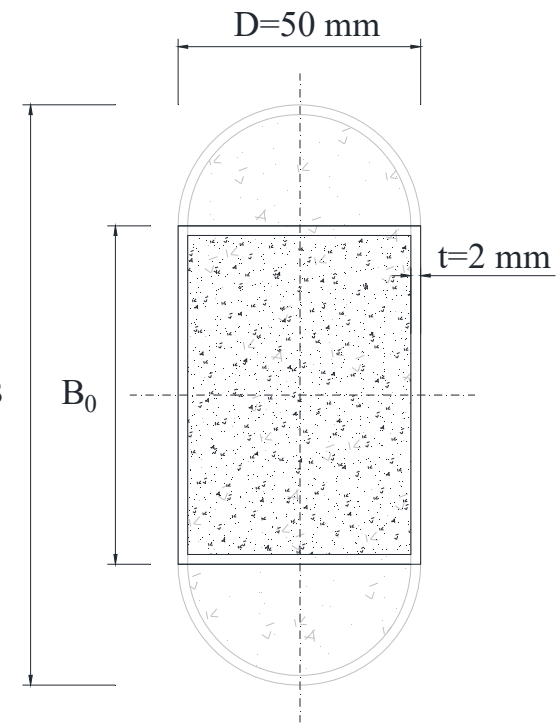

b)

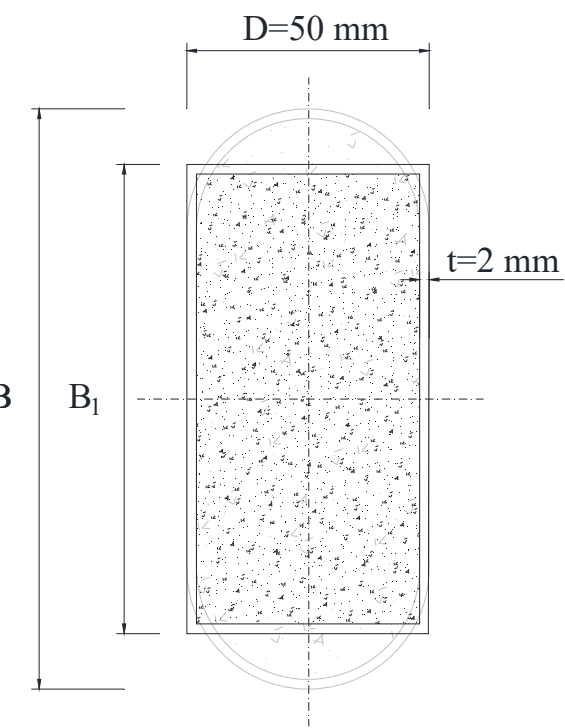

Fig. 13. Equivalent rectangular CFST cross-sections analysed. 


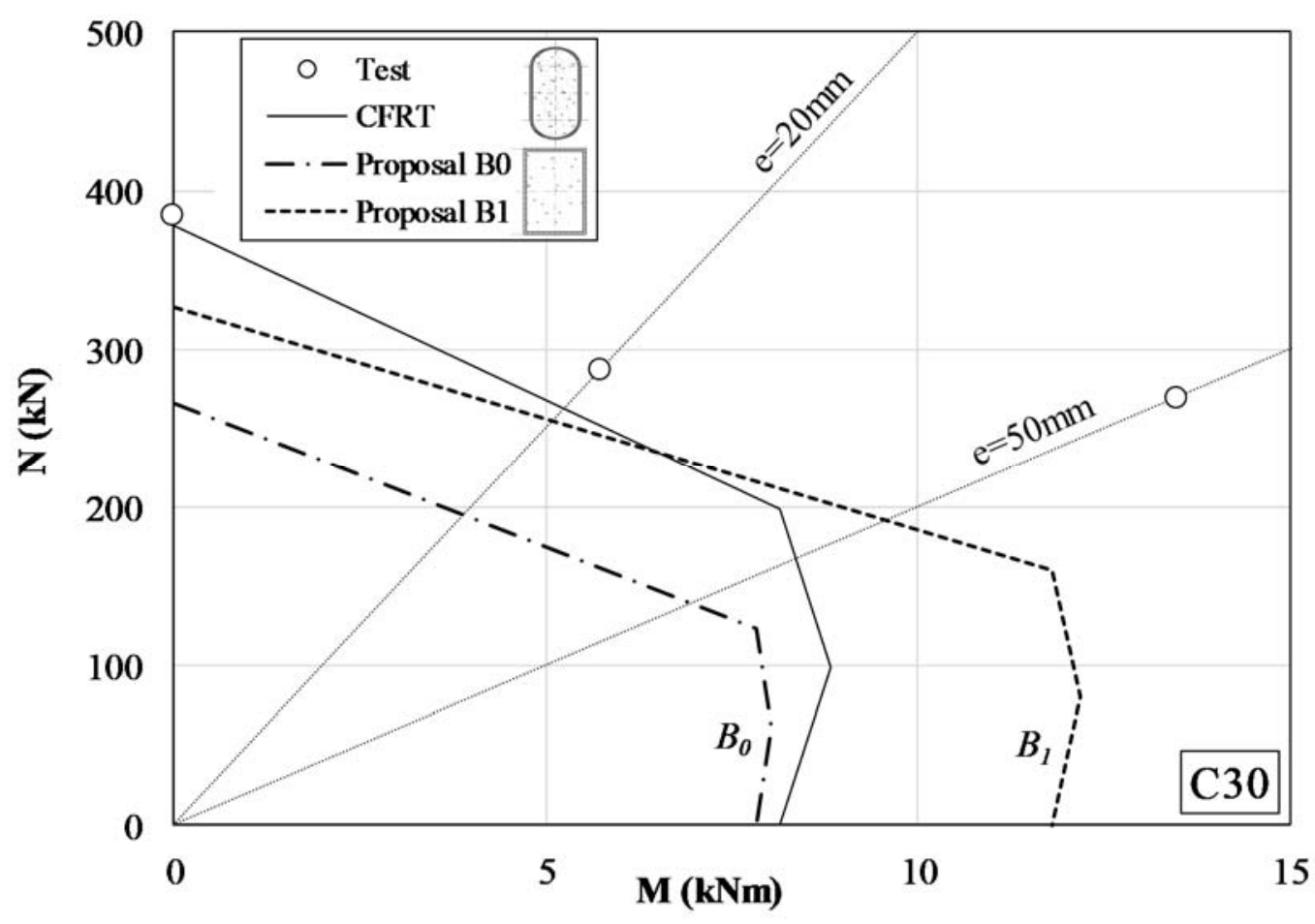

a) M-N curves for series 1 with NSC.

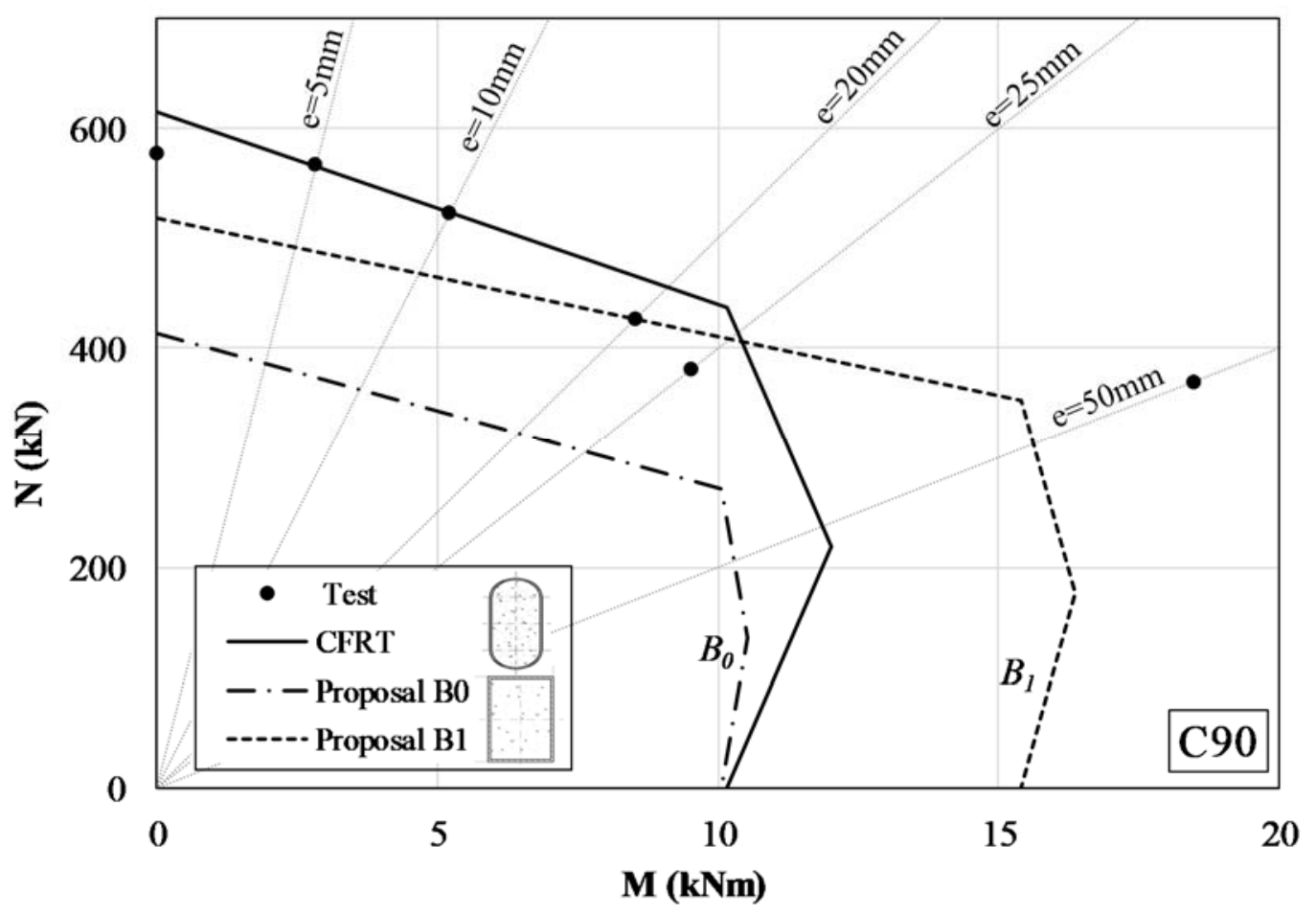

b) M-N curves for series 2 with HSC.

Fig. 14. Combined M-N interaction curves for the proposals. 


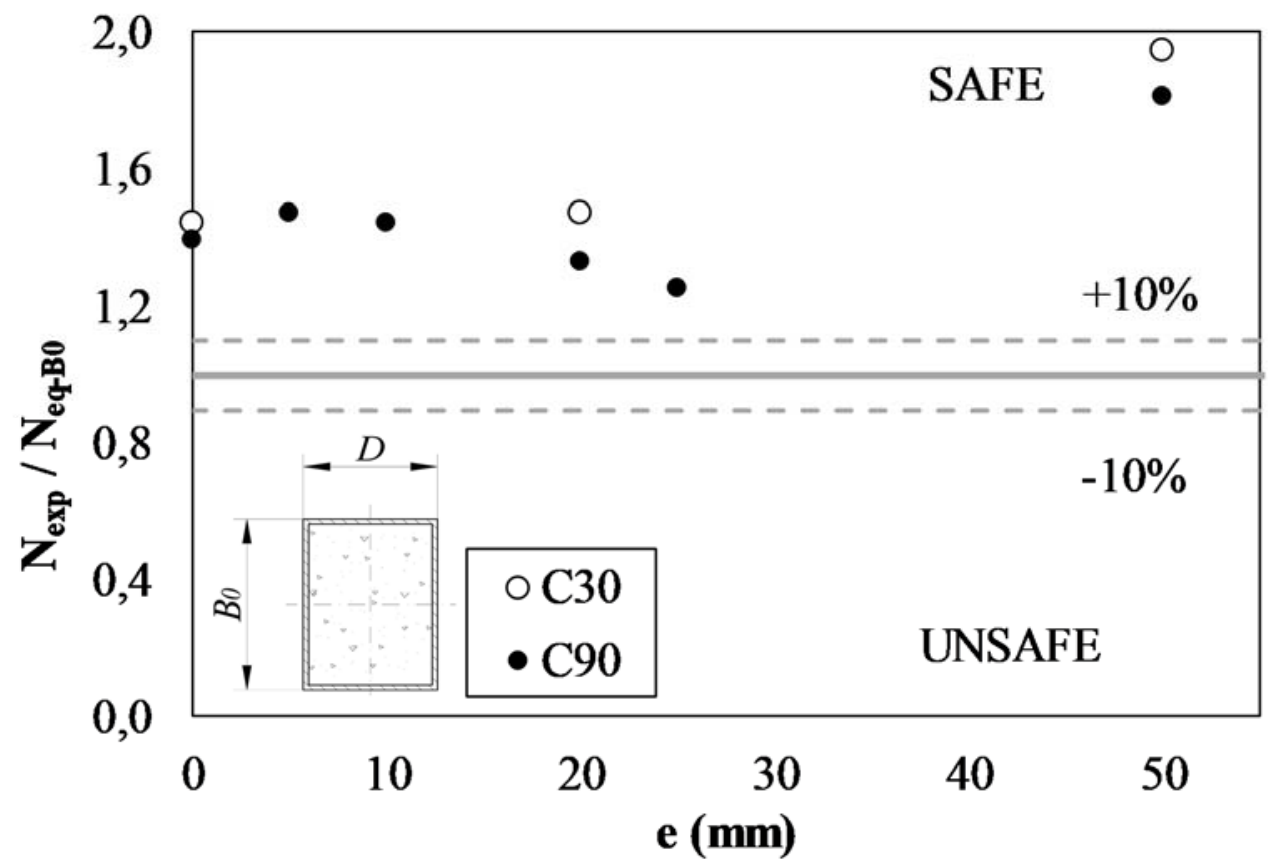

Fig. 15. Comparison between proposal $\mathrm{B}_{0}$ predictions and experimental ultimate loads.

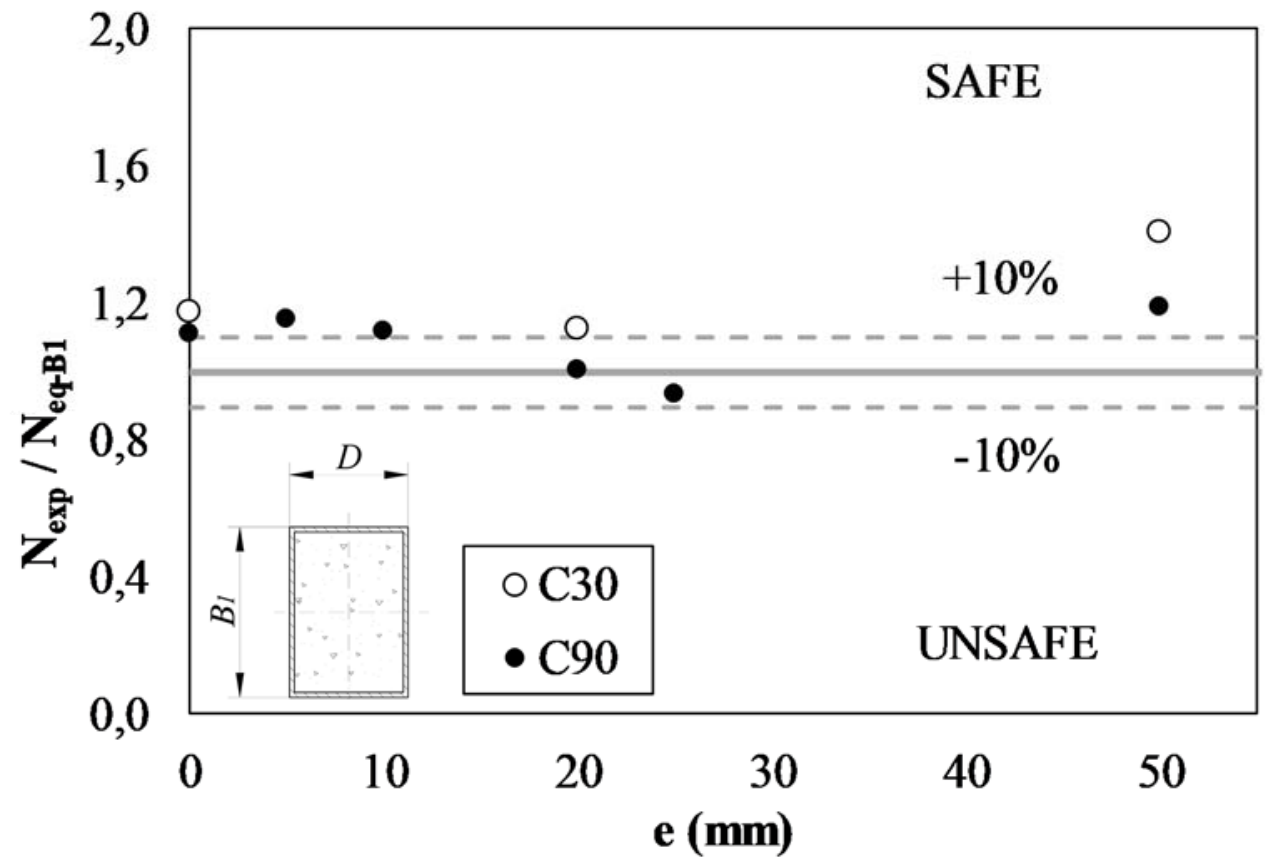

Fig. 16. Comparison between proposal $\mathrm{B}_{1}$ predictions and experimental ultimate loads. 
Table 1. Specimen details and test results

\begin{tabular}{llccccccc}
\hline & Name & $\begin{array}{c}f_{c} \\
(\mathrm{MPa})\end{array}$ & $\begin{array}{c}f_{y} \\
(\mathrm{MPa})\end{array}$ & $\begin{array}{c}f_{u} \\
(\mathrm{MPa})\end{array}$ & $\begin{array}{c}e \\
(\mathrm{~mm})\end{array}$ & $\begin{array}{c}N_{\text {exp }} \\
(\mathrm{kN})\end{array}$ & SI & CCR \\
\hline \multirow{5}{*}{ Series 1 } & RND_30_00 & 40.80 & 306.98 & 343.41 & 0 & 384.7 & 1.02 & 2.15 \\
& RND_30_20 & 40.80 & 306.98 & 343.41 & 20 & 286.3 & 0.76 & 1.61 \\
& RND_30_50 & 40.80 & 306.98 & 343.41 & 50 & 269.5 & 0.71 & 1.53 \\
& & & & & & & & \\
& RND_90_00 & 89.36 & 306.98 & 343.41 & 0 & 577.3 & 0.94 & 3.23 \\
& RND_90_05 & 89.36 & 306.98 & 343.41 & 5 & 566.3 & 0.92 & 3.18 \\
Series 2 & RND_90_10 & 89.36 & 306.98 & 343.41 & 10 & 522.7 & 0.85 & 2.94 \\
& RND_90_20 & 89.36 & 306.98 & 343.41 & 20 & 427.3 & 0.69 & 2.41 \\
& RND_90_25 & 89.36 & 306.98 & 343.41 & 25 & 381.0 & 0.62 & 2.15 \\
& RND_90_50 & 89.36 & 306.98 & 343.41 & 50 & 369.7 & 0.60 & 2.10 \\
\hline
\end{tabular}

Table 2. Mix design of concrete

\begin{tabular}{ccccccc}
\hline $\begin{array}{c}\text { Nominal } \\
\begin{array}{c}\text { Concrete } \\
\text { Strength (MPa) }\end{array}\end{array}$ & $\begin{array}{c}\text { Cement } \\
\left(\mathrm{kg} / \mathrm{m}^{3}\right)\end{array}$ & $\begin{array}{c}\text { Sand } \\
\left(\mathrm{kg} / \mathrm{m}^{3}\right)\end{array}$ & $\begin{array}{c}\text { Aggregate } \\
\left(\mathrm{kg} / \mathrm{m}^{3}\right)\end{array}$ & $\begin{array}{c}\text { Water } \\
\left(1 / \mathrm{m}^{3}\right)\end{array}$ & $\begin{array}{c}\text { Silica } \\
\left(\mathrm{kg} / \mathrm{m}^{3}\right)\end{array}$ & $\begin{array}{c}\text { Superpla } \\
\text { sticizer } \\
\left(\mathrm{kg} / \mathrm{m}^{3}\right)\end{array}$ \\
\hline $\mathrm{C} 30$ & 348 & 1065 & 660 & 220 & - & - \\
\hline $\mathrm{C} 90$ & 570 & 705 & 890 & 180 & 50 & 12.50 \\
\hline
\end{tabular}


Table 3. Ductility index

\begin{tabular}{clcccc}
\hline $\begin{array}{c}\text { Load } \\
\text { eccentricity }\end{array}$ & Name & $\begin{array}{c}\mathrm{N}_{\exp } \\
(\mathrm{kN})\end{array}$ & $\begin{array}{c}\delta \\
(\mathrm{mm})\end{array}$ & $\begin{array}{c}\delta 85 \% \\
(\mathrm{~mm})\end{array}$ & DI \\
\hline \multirow{2}{*}{ e=0 mm } & RND_30_00 & 384.7 & 7.65 & 8.88 & 1.16 \\
& RND_90_00 & 577.3 & 6.25 & 6.33 & 1.01 \\
\hline \multirow{2}{*}{ e=20 mm } & RND_30_20 & 286.3 & 5.64 & 10.41 & 1.85 \\
& RND_90_20 & 427.3 & 5.07 & 5.23 & 1.03 \\
\hline
\end{tabular}

Table 4. Experimental and predicted cross-sectional strengths

\begin{tabular}{|c|c|c|c|c|c|c|c|c|c|}
\hline & \multirow[b]{2}{*}{ Name } & \multirow{2}{*}{$\begin{array}{c}\mathrm{e} \\
(\mathrm{mm})\end{array}$} & \multirow{2}{*}{$\begin{array}{l}\mathrm{N}_{\exp } \\
(\mathrm{kN})\end{array}$} & \multicolumn{2}{|l|}{$\mathrm{EC} 4$} & \multicolumn{2}{|c|}{ Proposal $\mathrm{B}_{0}$} & \multicolumn{2}{|c|}{ Proposal $\mathrm{B}_{1}$} \\
\hline & & & & $\begin{array}{c}\mathrm{N}_{\mathrm{EC} 4} \\
(\mathrm{kN})\end{array}$ & $\begin{array}{l}\mathrm{N}_{\text {exp }} / \\
\mathrm{N}_{\mathrm{EC} 4}\end{array}$ & $\begin{array}{c}\mathrm{N}_{\text {eq-B0 }} \\
(\mathrm{kN})\end{array}$ & $\begin{array}{c}\mathrm{N}_{\text {exp }} / \\
\mathrm{N}_{\text {eq-B0 } 0}\end{array}$ & $\begin{array}{c}\mathrm{N}_{\text {eq-B1 }} \\
(\mathrm{kN})\end{array}$ & $\begin{array}{l}\mathrm{N}_{\text {exp }} / \\
\mathrm{N}_{\text {eq-B1 }}\end{array}$ \\
\hline \multirow{3}{*}{ Series 1} & RND_30_00 & 0 & 384.7 & 377.7 & 1.02 & 266.3 & 1.44 & 326.9 & 1.18 \\
\hline & RND_30_20 & 20 & 286.3 & 261.1 & 1.10 & 194.1 & 1.47 & 254.0 & 1.13 \\
\hline & RND_30_50 & 50 & 269.5 & 165.5 & 1.63 & 138.6 & 1.94 & 191.0 & 1.41 \\
\hline \multirow{8}{*}{ Series 2} & RND_90_00 & 0 & 577.3 & 614.8 & 0.94 & 413.7 & 1.40 & 518.0 & 1.11 \\
\hline & RND_90_05 & 5 & 566.3 & 563.6 & 1.00 & 385.2 & 1.47 & 490.5 & 1.15 \\
\hline & RND_90_10 & 10 & 522.7 & 521.4 & 1.00 & 361.3 & 1.45 & 466.6 & 1.12 \\
\hline & RND_90_20 & 20 & 427.3 & 453.5 & 0.94 & 321.5 & 1.33 & 425.1 & 1.01 \\
\hline & RND_90_25 & 25 & 381.0 & 410.6 & 0.93 & 304.7 & 1.25 & 407.1 & 0.94 \\
\hline & RND_90_50 & 50 & 369.7 & 235.2 & 1.57 & 203.9 & 1.81 & 310.5 & 1.19 \\
\hline & & & & Mean & 1.13 & Mean & 1.51 & Mean & 1.14 \\
\hline & & & & SD & 0.27 & SD & 0.22 & SD & 0.13 \\
\hline
\end{tabular}




\section{LIST OF FIGURE CAPTIONS}

Fig. 1. Different cross-sectional shapes for CFST columns: a) Circular; b) Rectangular; c) Elliptical; d) Round-ended.

Fig. 2. Column cross-section: a) Dimensions; b) Round-ended hollow steel sections.

Fig. 3. Test setup: a) Schematic view; b) Detail of load patterns; c) CFRT stub beam-column ready to be tested; d) Preparation of the steel tubes.

Fig. 4. Typical failure mode.

Fig. 5. Ultimate load vs eccentricity.

Fig. 6. Compression load versus shortening for: a) Series 1 C30; b) Series 2 C90.

Fig. 7. Strength index (SI) vs eccentricity.

Fig. 8. Concrete contribution ratio (CCR) vs eccentricity.

Fig. 9. Determination of ductility index from load-shortening curves: a) Columns RND_30_00 and RND_90_00; b) Columns RND_30_20 and RND_90_20.

Fig. 10. M-N interaction curve determination according to EC4.

Fig. 11. Combined axial force-bending moment $\mathrm{M}-\mathrm{N}$ interaction curve.

Fig. 12. Comparison between EC4 predictions and measured cross-sectional strengths.

Fig. 13. Equivalent rectangular CFST cross-sections analysed.

a) M-N curves for series 1 with NSC.

b) M-N curves for series 2 with HSC.

Fig. 14. Combined M-N interaction curves for the proposals.

Fig. 15. Comparison between proposal $\mathrm{B}_{0}$ predictions and experimental ultimate loads.

Fig. 16. Comparison between proposal $\mathrm{B}_{1}$ predictions and experimental ultimate loads.

\section{LIST OF TABLE CAPTIONS}

Table 1. Specimen details and test results

Table 2. Mix design of concrete

Table 3. Ductility index

Table 4. Experimental and predicted cross-sectional strengths 